IZA DP No. 9063

Who Is More Mobile in Response to Local Demand Shifts in China?

Dongdong Luo

Chunbing Xing

May 2015 


\title{
Who Is More Mobile in Response to Local Demand Shifts in China?
}

\author{
Dongdong Luo \\ Beijing Normal University \\ Chunbing Xing \\ Beijing Normal University \\ and IZA
}
Discussion Paper No. 9063
May 2015

IZA
P.O. Box 7240
53072 Bonn
Germany

Phone: +49-228-3894-0

Fax: +49-228-3894-180

E-mail: iza@iza.org

\begin{abstract}
Any opinions expressed here are those of the author(s) and not those of IZA. Research published in this series may include views on policy, but the institute itself takes no institutional policy positions. The IZA research network is committed to the IZA Guiding Principles of Research Integrity.

The Institute for the Study of Labor (IZA) in Bonn is a local and virtual international research center and a place of communication between science, politics and business. IZA is an independent nonprofit organization supported by Deutsche Post Foundation. The center is associated with the University of Bonn and offers a stimulating research environment through its international network, workshops and conferences, data service, project support, research visits and doctoral program. IZA engages in (i) original and internationally competitive research in all fields of labor economics, (ii) development of policy concepts, and (iii) dissemination of research results and concepts to the interested public.
\end{abstract}

IZA Discussion Papers often represent preliminary work and are circulated to encourage discussion. Citation of such a paper should account for its provisional character. A revised version may be available directly from the author. 


\section{ABSTRACT}

\section{Who Is More Mobile in Response to Local Demand Shifts in China?*}

In this paper, we use two nationally representative datasets to examine the population adjustment of demographic groups in response to regional demand shifts between 2000 and 2005. Results from OLS regressions show that population changes of less educated groups are more associated with changes in total city working hours than population changes of educated groups. These findings explain increases in skill premia in coastal regions after China's entry into the WTO, but it does not mean that the former groups are more responsive to demand shocks, because changes in city working hours also reflect other forces such as supply shocks. Using an IV strategy, we find that educated workers are more responsive to demand shocks than those who are less educated. In addition, old subgroups are particularly inert in responding to demand shocks. Our results also suggest that China's household registration (Hukou) system prevents the mobility of urban residents more than it prevents the mobility of rural residents. We propose that Hukou reform should not only abolish the agricultural vs. non-agricultural division, but also change the decentralized (local vs. nonlocal) feature of the system.

JEL Classification: J23, R23

Keywords: local demand shift, population adjustment, Hukou

Corresponding author:

Chunbing Xing

School of Economics and Business Administration

Beijing Normal University

No. 19 Xinjiekouwai Dajie

Beijing, 100875

China

E-mail: xingchb@bnu.edu.cn

\footnotetext{
*We are grateful to Minghai Zhou, Shi Li, Chuliang Luo, Quheng Deng, and seminar participants at the University of Nottingham, Ningbo. We are also grateful to the National Natural Science Foundation of China (No. 71103019) and the Fundamental Research Funds for the Central Universities for their financial support.
} 


\section{Introduction}

In 2007, the GDP per capita of China’s richest province, Shanghai, was 10 times of that of the poorest province, Guizhou (National Bureau of Statistics, 2008). In addition, the urban-rural income ratio in China hovered above 3:1, among the highest in the world. These numbers reflect a striking regional imbalance during China's period of high economic growth in the last three decades. The labor market responds to local demand shifts in several ways, ${ }^{1}$ one of which is migration. In 2012, over 160 million individuals from rural China migrated to richer areas for well-paid jobs. Meanwhile, many workers from within urban areas migrate to other cities for better employment opportunities (Jason, et al. 2014). The demographic characteristics of such a large number of migrants are not only important for us in understanding China's urbanization patterns, but are also crucial to explaining the economic performance of different regions and income inequality both within and between regions. In this paper, we ask the following questions: (1) Do workers of different education levels and ages respond to local demand shocks differently? If so, how do their responses differ? (2) Does China’s Hukou system (see detailed discussion of the Hukou system in the background section) restrict the mobility of workers? If so, how?

The first question has been raised in public and academic discussions, but it is not well addressed. Take the differential responses of educated and less educated workers for example. Some argue that educated workers are more responsive to regional demand shifts than less educated workers, because the Hukou system treats them better, and they have lower migration costs and higher gains. ${ }^{2}$ On the other hand, given the large pool of rural workers and the much lower income levels in rural China, it is probable that the less educated rural workers are more responsive to demand shifts in coastal cities despite the fact that most are denied urban Hukou. The

\footnotetext{
${ }^{1}$ Such as the adjustment in working hours, labor participation rates, unemployment rates, and population.

${ }^{2}$ See Topel (1986) and Bound and Holzer (2000) for studies in the U.S context.
} 
latter hypothesis seems to be consistent with Whalley and Xing's (2014) finding that while the wages of skilled workers increased in coastal regions relative to hinterland China between 2002 and 2007, the regional wage gap for the unskilled decreased. ${ }^{3}$ As no consensus has been reached, systematic evidence and rigorous analysis are needed.

The responsive pattern for populations of different ages has been discussed less often, but it is of great importance for regional development. In addition, we raise a rarely discussed question in this paper: Does the Hukou system restrict the mobility of rural workers more than it does for urban workers? The literature usually stresses the role of China's Hukou system in restricting rural to urban migration, but seldom discusses its role in restricting the mobility of workers with urban Hukou. Finally, the labor force can respond to the increased demand for labor by working longer hours-a strategy that differs across demographic groups. Although Hukou is a major aspect of labor market adjustment, little research has been conducted on this relationship.

We use a random sample of the population census for 2000 and a one-fifths random draw from the 1 percent population survey for 2005 to investigate population adjustment to local demand shifts during this period. The period of 2000 to 2005 is crucial in China's economic growth. After China entered the World Trade Organization (WTO) in 2001, exports surged and trade activity was mainly concentrated in coastal regions. Between 2000 and 2005, the Chinese economy grew rapidly at an annual rate of 9 percent, equivalent to a 15-year growth with an annual growth rate of 3 percent. Thus, this period of regional unbalanced growth provides a good opportunity to answer the questions of this paper.

Following Bound and Holzer (2000), we measure adjustments for each demographic group with changes in population size, total hours worked, and average

\footnotetext{
${ }^{3}$ However, this research uses the urban household survey, which does not include migrant workers. In addition, it does not consider demand shifts explicitly and conclusions from that research may suffer from an endogeneity problem.
} 
working hours. As for local demand shifts that cannot be observed directly, we use growth in total local hours (total hours worked in one city) as a proxy. Results from OLS regressions show that changes in population of the less educated groups are associated with changes in total city working hours more than that of the educated groups. This explains the increases in the skill premia in coastal regions after China's entry into the WTO.

As changes in total hours worked also reflect supply effects, we generate an instrumental variable following Bartik (1991), which mainly reflects the influence of national demand forces in a specific locality. Using the IV strategy, we find that more educated workers are more responsive to demand shocks than the less educated. Old subgroups are particularly inert in responding to demand shocks. Our results also suggest that the decentralized Hukou system prevents the mobility of urban residents more than it does for rural residents. Finally, our results show that less educated workers are more likely to adjust to positive demand shifts by working more hours.

Our results suggest that although China's labor market is flexible in terms of population adjustment to labor demand shifts, the Hukou system still hinders mobility of workers. In particular, the Hukou system hinders the mobility of workers with urban Hukou to a larger extent than it does for those with rural Hukou.

This paper contributes to the literature in three ways. First, we are among the first to document and analyze population adjustment to regional demand shifts in the context of China. Existing research mainly focuses on the U.S. labor market (Bartik, 1991; Topel, 1986; Bound and Holzer, 2000; Blanchard and Katz, 1992). Second, this research amplifies understanding of the Hukou system. Existing research mainly focuses on the rural vs. urban dimension and its impact on rural-to-urban migration. In this paper, we emphasize the decentralized (local vs. non-local) feature of the Hukou system and its impact on the migration of residents with urban Hukou. Third, results presented in this paper help us explain the behavior of regional income gaps, which 
has been studied extensively (Kanbur and Zhang, 2005; Lin et al., 2004). Few studies have considered demand factors and population adjustment explicitly.

The paper proceeds as follows. Part II presents background and literature on demand shifts and population adjustments. Part III describes our data, laying out some facts about regional changes between 2000 and 2005. We discuss our empirical method in detail and report estimates of the relative mobility of various demographic groups in Part IV. Skill bias and factors that may increase the migration cost of workers in urban China are discussed in Part V. Part VI presents our conclusion that more educated and young workers are more responsive to demand shocks than less educated and old workers and that the decentralized Hukou system prevents the mobility of urban residents more than it does for rural residents.

\section{Background and Literature Review}

In China's reform period, different regions experienced drastically different paths of economic growth, and the regional income gap (including the rural-urban income gap) became the major contributor to the sharply increased income inequality (Gustafsson et al., 2008; Chen et al., 1996). The fact that demand shifts are regionally concentrated plays an important role in shaping the regional gap.

First, economic growth is often associated with changes in economic structure. A national change will have different impacts on regions, as each region has a different economic structure historically. Another reason for regional unevenness is different exposure to trade activity. The policy of opening up was first implemented in the east and led to rapid growth of exports and FDI inflows. In 1995, the average share of exports in GDP in coastal provinces was 32 percent, while that of non-coastal provinces was below 7 percent. ${ }^{4}$ China experienced a sharp increase in trade activity

\footnotetext{
${ }^{4}$ Coastal provinces include Beijing, Fujian, Guangdong, Hainan, Hebei, Jiangsu, Liaoning, Shandong, Shanghai, Tianjin, and Zhejiang. Non-coastal provinces include Anhui, Gansu, Guangxi, Guizhou, Henan, Heilongjiang, Hubei, Hunan, Jilin, Jiangxi, Inner Mongolia, Ningxia, Qinghai, Shanxi, Shaanxi, Sichuan, Tibet, Xinjiang, Yunnan, and Chongqing. Export shares are first calculated for each province and then averaged for coastal and non-coastal regions. The shares for 2007 are calculated in the same way.
} 
in a relatively short period after its entry into the WTO (Wan et al., 2007; Branstetter and Lardy, 2006), and most of the increase was in coastal regions. By 2007, the average export share in GDP in coastal provinces had reached 45 percent, while that of non-coastal provinces was still below 8 percent. Along with rapid export growth, China's exports were becoming more sophisticated, with resources moving from agriculture and textiles into machinery, electronics, and assembly (Schott, 2006; Amiti and Freund, 2008; Wang and Wei, 2008). ${ }^{5}$

These regional patterns reflect, in part, the policies of the Chinese government. In the earlier reform period, the central government offered not only preferential policies, but also more investment in coastal regions to encourage exports and attract FDI. The five Special Economic Zones (SEZs) ${ }^{6}$, for example, are all in coastal regions (Wang and Wei, 2008). In the late 1990s, because of the widening regional gap, preferential policies were more often designed for the central and western regions. Many other policies were also location-specific, such as policies for developing the Pudong New District in Shanghai, the Binhai New District in Tianjin, and the more recent strategy to revitalize the old industry base of the Northeast. These initiatives often involve preferential policies implemented by the local and central governments, such as lower income tax rates for foreign invested enterprises, fewer entry barriers into the finance and service sectors, more favorable treatment for land use permissions, and subsidies for industrial upgrading. All these policies tended to increase local demand for labor and encourage migration across regions.

However, the Hukou system, which was originally designed to control rural to urban migration in the 1950s by registering household members in designated locations, still imposes high moving costs for migrants. One's Hukou status is categorized by both socio-economic eligibility (agricultural and non-agricultural

\footnotetext{
${ }^{5}$ There have also been efforts to relate China's globalization process to inequality. See Zhang and Zhang (2003), Wei and Wu (2003), Wan et al. (2007), and Cai et al. (2009). Using aggregate data, these papers focus on the relationship between globalization and regional disparity.

${ }^{6}$ The five coastal cities are Shenzhen, Zhuhai, Shantou, Xiamen, and Hainan.
} 
Hukou) and registered residential location (local and non-local Hukou) (Chan and Buckingham, 2008). ${ }^{7}$ Hukou status in a registered location confers specific local benefits, including access to health care, free public education, legal housing, and access to jobs. To migrate permanently, one must change one's registration location. ${ }^{8}$ The government exerted tight controls over both the process and the number of such moves. Temporary migrants, who cannot change registration location, also needed official approval. To migrate without authorization, people were vulnerable to round-ups and deportation to their original province or village. Local citizenship benefits were inaccessible to temporary migrants.

Hukou policies have been becoming more flexible since the 1980s. A major change was the decentralization of Hukou management, with many local governments receiving full power to determine their own criteria and the number of new permanent Hukou registrations they would grant. It has become easier for workers and households to transfer their registrations to other locations (in particular, from small- to medium-sized cities), and temporary residence permits are being granted more often. Also, it became possible for some to migrate and get a job without a valid permit. But for temporary migrants, educated or less educated, local public services remain either inaccessible or expensive.

Compared to less educated workers, educated workers are more likely to secure local Hukou when they migrate. However, although educated workers are more likely to obtain urban local Hukou, the number of such changes is strictly controlled in large coastal cities. For educated workers who cannot secure a local Hukou, the opportunity

\footnotetext{
${ }^{7}$ The first classification determines entitlement to state-subsidized food grain and other benefits. The second classification defines one's rights to participate in many activities in a specific locality. One's Hukou status is determined by birth, following his/her parents' status.

${ }^{8}$ Due to significant differences in employment opportunities and welfare and benefit entitlements, there is a strong incentive for rural residents to change their Hukou registration from rural to urban. Prior to the late 1990s, such changes also required approval from the state to convert Hukou status from agricultural to non-agricultural. This change can only be made through certain channels and complicated procedures, and these channels generally favor individuals with more skills and/or special achievements. Going to college has been a major channel increasing the probability of a favorable Hukou status. Other channels that increase this probability include serving in the military, being recruited by SOEs or the government (Wu and Treiman, 2004; Fan, 2008), rural residents' lands being occupied by urban construction projects (Wong and Huen, 1998), and rural households purchasing urban housing (Deng and Gustafsson, 2006).
} 
costs of moving to better paid cities are probably high, because they need to give up decent and secure jobs either in rural non-farm sectors or in small- to medium-sized cities. ${ }^{9}$ In contrast, many less educated rural workers migrate for better paying jobs without obtaining local Hukou (note that the current Hukou system does not prevent such movements). They would have engaged in farming jobs with low incomes had they not migrated. ${ }^{10}$ Until now, there is little systematic evidence showing which type of workers is more restricted by the Hukou system.

Demand shifts and population adjustments have been studied mostly in the context of the U.S. labor market. Most studies show that the more educated workers have relatively high rates of population adjustment in response to demand shock. For instance, Topel (1986) studied the processes of wage and employment dynamics within local labor markets using a time series of cross-sectional files from the Current Population Surveys of $1977-1979$. He found that a positive relative shock to local labor demand increases relative wages within a locale, and demand-generated wage differentials are significantly smaller among more educated workers and negligible among more experienced workers. Based on the Public Use Micro Samples of the Census of Population in 1980 and 1990, Bound and Holzer (2000) explored the effects of labor demand shifts and population adjustments across metropolitan areas on the employment and earnings of various demographic groups during the 1980s. They found that the effects of demand shifts on wage and employment were greatest among the least-experienced, the less-educated, and black workers, and less-educated workers and black workers showed fewer population adjustments in response to these demand shifts.

\footnotetext{
${ }^{9}$ This is the case considering that non-coastal cities have a higher share of workers employed in State Owned Enterprises (SOEs).

${ }^{10}$ In a related study, Zhao (1997) finds that in Sichuan province rural residents with relatively higher education levels (high school graduates) tend to find jobs in local non-farm sectors rather than in cities, mainly because of discrimination and higher living costs in urban areas (especially when compared to a decent, well-paid job and low living costs in rural areas). The pattern that low skilled rural labor force has higher migration rates is also observed in the U.S. around the period of two world wars and in the 1920s (Bound and Holzer, 2000).
} 


\section{Data Description}

We use a random sample of the Census for 2000 and a one-fifths random draw from the 1 percent population survey for 2005 to estimate the differential population adjustments in response to local demand shifts between demographic groups during this period. Both databases cover 31 provinces (or municipalities) in China and contain 1,180,110 and 2,585,481 individuals, respectively, with rich information including gender, age, education level, Hukou status, industry, and working time. For consistency, we classify education levels into four categories: primary school or below, junior high school, senior high school, and college or above. Industries are reclassified into 19 broad categories according to those set out by the National Bureau of Statistics. ${ }^{11}$ The population survey of 2005 collected information on hours worked per week, whereas the 2000 census recorded days worked per week. We assume that people work eight hours per day and multiply days worked per week by eight to get weekly working hours for $2000 .^{12}$ For our analysis, we keep individuals aged 16 to $54^{13}$ and exclude students, incapacitated persons, and retirees in both 2000 and 2005. Observations in Tibet are dropped, as there are few observations available. Table 1 provides summary statistics of the data.

As shown in Table 1, the average age and education level of the labor force increased between 2000 and 2005. The average age increased from 34.67 in 2000 to 35.96 in 2005. The share of the population with a college diploma (or above) increased from 5.2 percent in 2000 to 8.4 percent in 2005, which reflects the expansion of college enrollment in China since 1999. The share of the workforce with urban Hukou increased from 22.3 percent in 2000 to 24.9 percent in 2005. It seems

\footnotetext{
${ }^{11}$ Observations in the industry of foreign organization are dropped, because there are few observations.

12 This assumption is based on the fact that most subjects report their working hours as a multiple of eight or ten. In the Census for 2005, more than 28 percent of individuals reported 40 hours worked in one week, and more than 23 percent reported 56 hours. Correspondingly, about 26 percent and 50 percent of workers chose 5 days and 7 days as their working days in one week. Hence, we tend to believe that people usually report their working hours per week by multiplying their working days by eight. Robustness checks show that our results are not sensitive to how we adjust the working time.

${ }^{13}$ Although the age ranges of the labor force in China are 16-54 for females and 16-59 for males, we use the former range for both genders. The results do not change significantly when we use other age ranges.
} 
that the urban Hukou quota fails to meet the demand of an increasing number of college graduates, let alone an even larger number of less educated migrant workers.

The data also indicates that China's economy experienced rapid and unbalanced growth from 2000 to 2005. Changes in the log of total working hours by industry are presented in Figure 1. The IT (Information Transmission, Computer Services and Software) industry developed most quickly, increasing by more than 800 percent. The second fastest growing industry is household services (Services to Households and Other Services), followed by the real estate industry and the construction industry. On the contrary, the agricultural industry (Farming, Forestry, Animal Husbandry and Fishery) experienced declines in total working hours. The growth of China's economy was concentrated in the secondary and tertiary industries, which reflects industrial upgrading and China's emergence as the world’s factory.

Table 2 provides growth in total hours worked and labor force population across provinces between 2000 and 2005. Total hours in coastal provinces, like Fujian, Guangdong, and Tianjin, increased at an annual rate of over 2 percent, while those in the southwest regions, such as Guizhou, Guangxi and Sichuan, decreased sharply. In addition, changes in total hours worked are strongly positively related to changes in labor force population, suggesting that the labor market responds to local demand shifts through migration. ${ }^{14}$

Regional differences still exist when we look at industry development. Figure 2 provides growth in total working hours in the four fastest-growing industries across provinces. Growth in the IT industry is concentrated in coastal provinces, such as Liaoning, Shandong, Jiangsu, and Guangdong. As for the $2^{\text {nd }}$ fastest growing industry, domestic services, coastal provinces such as Hebei, Shandong, and Jiangsu, also outperformed hinterland China, as real estate and construction. The fact that coastal provinces grow more quickly than inland provinces reflects the regional imbalance in

\footnotetext{
${ }^{14}$ As for other adjustments, such as labor participation rates and unemployment rates, both changed little in urban areas from 2000 to 2005 (see Appendix).
} 
China's rapid development, which also suggests the presence of local demand shifts between 2000 and 2005.

To see the response to local demand shifts of different demographic groups, we categorize individuals into cells on the basis of four education groups, four age groups (16-25, 26-35, 36-45, and 46-54), two gender groups, and Hukou status (agricultural vs. non-agricultural) within each city for both years. For each city, we measure population adjustments of each cell with changes in the log of population size and measure total labor adjustment of each cell with changes in the log of total hours worked. Summary statistics on changes in the log of our three outcomes (average hours worked per week, population, total hours worked) are presented in Table 3.

Between 2000 and 2005, the less educated (primary school or less and junior high school) experienced declines in average hours worked per week, while the more educated (senior high school and college or above) experienced increased working hours. As for population, the growth in the number of workers with a college background is dramatic compared to the falling or slight increase in other groups. This difference is more evident in the young groups. Non-college workers aged 16 to 35 decreased considerably in population size, reflecting the effect of college expansion. Although there is an increase in average hours worked for young workers with senior high school degrees, their total hours worked dropped due to the rapidly decreasing population. In addition, the female population increased more or decreased less than the male population for most subgroups, especially for educated females, indicating an increase in female labor participation. Finally, the large standard deviation of population, nearly twice the average population size, indicates that there exist wide variations in the changes across regions in China between 2000 and 2005.

\section{Empirical Analysis}

We examine the relative mobility of various groups by exploring the relationship between local demand shifts and population adjustments. We are particularly 
interested in the differential responses of educated vs. less educated workers, of old vs. young workers, and of agricultural vs. non-agricultural workers. We start our empirical analysis with a standardization procedure, because differential changes in average weekly working hours, population, and total hours worked may result from differences in demographic compositions across cities. For example, when we look at the adjustments of the more educated workers in two cities, one city might witness a sharper increase in population than the other, because its population is younger. This difference can be taken care of by the following standardization procedure: after calculating changes in labor market outcomes for each cell in each city, we run regressions on dummies for cities and demographic cells. Specifically, letting $y_{i j m h k}$ represent the change in an outcome (hours, population, or total hours worked) for the $i$ th education, the $j$ th experience, the $m$ th sex group, and the $h$ th Hukou status in $k$ th city, we estimate the following equations:

$$
y_{i j m h k}=\beta_{i j m h}+\beta_{k}+\varepsilon_{i j m h k}
$$

Regressions are weighted using the shares of the relevant demographic group in total hours worked in the city (averaged between 2000 and 2005). Regressions are run separately for subgroups by education (senior high school or above vs. junior high school or below), age (16-35 age group vs. 36-54 age group), and Hukou status. $\beta_{k} \mathrm{~s}$ represent the average outcomes standardized for demographic differences across cities, which are then regressed on the demand shift to generate the results reported in the following tables. In particular, the second-stage regressions are run as follows:

$$
\hat{\beta}_{k}=\alpha_{0}+\alpha_{1} \cdot \text { city_ }_{-} \text {hour }_{k}+\mu_{k}
$$

where city_hour ${ }_{k}$ denotes changes in the log of total working hours in city $k$, which is used as a proxy for the unobservable demand shift that city $k$ experienced. Regressions are weighted using the share of overall population in the sample accounted for by the city (averaged between 2000 and 2005). Because total local 
hours can also be affected by local labor supply shift, OLS estimation will confound the effects of labor supply and demand shifts, leading to biases in the effects of demand shifts on labor market outcomes. We use an index for demand based on national industrial growth of working hours as an instrument for demand shifts. ${ }^{15}$ The index is constructed as follows:

$$
\hat{\eta}_{k}=\sum_{j} \gamma_{j k} \eta_{j}
$$

where $\hat{\eta}_{k}$ represents predicted growth of hours worked in city $k, \gamma_{j k}$ represents the share of total hours worked accounted for by industry $j$ in city $k$ in $2000,{ }^{16}$ and $\eta_{j}$ represents the change in the log of total hours worked in industry $j$ nationally between 2000 and 2005. As changes in logs represent growth rates, $\hat{\eta}_{k} \mathrm{~s}$ are predicted growth rates of total working hours in city $k$ based on industrial growth at the national level and the historical industrial structure of the city. This index is a valid instrument variable if the national growth rates are uncorrelated with local labor supply shock. This will be true as long as an industry is not concentrated in a particular city-a condition that is clearly satisfied at the 19-broad-category level.

\section{OLS Results}

We start with the OLS regression results. Although the results may cofound the effects of local supply shocks, they provide valuable hints regarding the evolution of regional income gaps of different groups. Results in Table 4 (columns 1 to 3) suggest that the labor market adjustments are significantly correlated with local demand shifts. Both the size of population and their working hours increased as city hours increased, and the adjustment in population is larger than that of an average worker's working hours. Two important features emerge when we compare the results of different

\footnotetext{
${ }^{15}$ The index was created by Timothy Bartik (1991) and used by Blanchard \& Katz (1992) and Bound \& Holzer (2000).

${ }^{16}$ We also use the average share of 2000 and 2005, and the results do not change significantly.
} 
subgroups. First, the extent of adjustment, both in population and in working hours, is larger for the low education group than for the high education group. This pattern remains unchanged when we look at the responses of young and old groups separately, with the differences being larger for the young groups than for the old groups. These results are at odds with the prevailing view that educated workers are more mobile than the less educated. However, they are consistent with the findings in Whalley and Xing (2014), who show that the regional dispersion of wages for unskilled workers decreased between 2002 and 2007, while the same for skilled workers increased during this period. Of course, this feature could also be caused by supply shocks, and we will discuss this possibility in the following section. The second feature is that the labor market adjustment of the younger groups is associated with changes of total city working hours to a larger extent than that of the old groups.

We next perform the same exercises for the subgroups with agricultural and non-agricultural Hukou separately (changes in total working hours at the city level are still used as the independent variable), the results of which are reported in Table 5 and Table 6, respectively. For the subgroups with agricultural Hukou, the results (columns 1 to 3, Table 5) are similar to those reported in Table 4. The estimated effects are slightly larger for the agricultural Hukou subgroups than the full sample, which is especially true for the young groups. The less educated are more responsive to changes in city total working hours, which is consistent with existing findings that highly educated individuals with agricultural Hukou are less likely to migrate (see Zhao 1997 for example). The results reported in columns 1 to 3 in Table 6 suggest that the changes in the total working hours of the subgroups with non-agricultural Hukou are less associated with changes in city total working hours than that of subgroups with agricultural Hukou. This is consistent with the impression that urban residents with non-agricultural Hukou are less mobile than rural migrant workers. In terms of population adjustment, low education groups with non-agricultural Hukou are less 
responsive to demand shifts, but their working hours changed to a larger extent than the high education groups.

The area in which an individual currently resides or works is classified into three categories in the data: city, town, and village. City and town are defined as urban areas and villages are defined as rural areas, consistent with the definition used by the NBS. In the following section, we consider only individuals currently residing in cities and towns. We drop observations in villages when we construct all the variables, including the independent variable city_hour. The results are reported in Table 7, and the patterns are similar to those observed in the above exercises. Within urban areas, it remains true that the less educated are more responsive to local demand shifts than the educated subgroups. The results also show that the subgroups with agricultural Hukou are more responsive to demand shifts than those with non-agricultural Hukou. Finally, the coefficients on population adjustment for the low educated subgroups with agricultural Hukou are significantly greater than one, suggesting some agglomeration or multiplying effects.

\section{Results}

The changes in total hours at the city level may reflect shifts in labor supply. For example, the college education expansion initiated in the late 1990s could exogenously attract high school graduates to places with more colleges, which tends to increase the labor supply of those places. In this case, the coefficients in the above OLS regressions can at most be interpreted as correlation, rather than indicating the response of various demographic groups to demand shifts. To alleviate this concern, we use the predicted growth of log working hours as the instrumental variable of the independent variable city_hour. The significant positive relationship between the constructed IV and the independent variable is depicted in Figure 3, and the regression result is as follows: 


$$
\text { city_hour }_{k}=0.021+0.947 \hat{\eta}_{k} \quad \mathrm{~F}(1,306)=71, R^{2}=0.19
$$

The R-squared of 0.19 suggests that the predicted growth in city hours based on national industrial growth and city-specific industry structure can explain much of the variation in the changes in working hours across cities. The F statistics of 71 suggests that the instrumental variable is relevant. Obviously, over 80 percent of the variation in city hour growth is caused by factors other than differential industrial growths. The coefficient on $\hat{\eta}_{k}$ being close to one (0.947) indicates that there is no multiplying effect of national industry growth on local working hours. This finding is in contrast with what was found in the U.S. labor market by Bound and Holzer (2000), who show a multiplier of roughly two. This may suggest that potential agglomeration effects do not take place in China due to restrictions of factor mobility across regions.

The IV regression results are reported in columns 4 to 6 of Table 4. A major change from the OLS results is that low education individuals are less responsive to demand shifts in terms of population adjustment than high education workers. Another difference is that low educated individuals aged 35 to 54 are not responsive to demand shifts in terms of population adjustment, and they respond to demand shifts mainly through adjusting working hours. However, it remains unchanged that young workers are more responsive to demand shifts than old workers in terms of population change and vice versa in terms of changes of working hours. These patterns remain largely unchanged when we look at the results for subgroups with agricultural Hukou and non-agricultural Hukou, as reported in columns 4 to 6 in Table 5 and Table 6. Two features are worth mentioning. First, the agricultural Hukou subgroups are more responsive to demand shifts than those with non-agricultural Hukou both in terms of population and working hours. Second, neither of the estimated coefficients for the old workers with non-agricultural Hukou is significant, suggesting that they do not respond to local demand shifts through migration across regions.

Thus, the IV results suggest that Hukou plays an important role in influencing the adjustment of China's labor market in response to local demand shifts. However, the 
results of this paper are not in line with most existing studies. The latter usually emphasize the function of the Hukou system in restricting the mobility of rural workers. Our results suggest that workers with non-agricultural status (especially those of low education levels and with higher ages) are rather unresponsive to demand shocks.

The difference between OLS results and IV results is also informative. For population change of the less educated subgroups, the coefficients on changes in total city working hours using IV strategies generally become smaller than those using OLS estimation. These differences suggest that the correlation we observe in the OLS regressions might be caused by other factors such as supply shocks. On the other hand, for population change of the educated and young subgroups, the coefficients become even larger when IV strategy is used. This suggests multiplier (or agglomeration) effects: once a positive demand shock sets in by exogenous industrial change, there will be population adjustment of a larger extent. This agglomeration effect is diluted when we run simple OLS regressions. For changes in working hours per worker, the coefficients become larger in all exercises when IV is used.

It is particularly interesting to perform a similar exercise on urban areas, as seen in the OLS exercises reported in Table 7. Unfortunately, the instrumental variable strategy does not work, because the predicted growth of city working hours is not correlated with actual changes of city working hours (see Figure 4). The absence of positive correlation is an interesting feature; we leave this analysis for future research.

\section{Robustness Checks}

An important shortcoming of this paper is that we do not have consistent working time information for 2000 and 2005. In 2000, information was collected on hours worked per week, but in 2005 data was collected only on days worked per week. As mentioned, we multiply days worked per week by eight to get working hours per week for 2000. In this section, we conduct two robustness checks by (1) using an alternative method of adjustment and (2) focusing on population. 
Previously, we multiplied days worked in 2000 by eight to compare with working hours in 2005. However, there are many people whose working hours are between those multiples of eight. For example, in 2005 about 5 percent, 7 percent, and 13 percent of the observations' working hours are between 24 and 32 hours, 48 and 56 hours, and above 56 hours (see Figure 5). The presence of these cases might weaken the comparability of working time. Hence, we divide hours worked per week by eight and round quotients to get working days per week for $2005 .{ }^{17}$ With such time adjustment, subjects' working time in 2000 and 2005 are much more consistent and comparable (see Figure 5).

Table 8 and Table 9 present the effects of demand on outcomes by age, education, and Hukou status (Table 8 for subgroups with agricultural Hukou and Table 9 non-agricultural). Our main conclusions do not change significantly. First, OLS results show that the population adjustment of the less educated groups is more associated with a change in total working hours than that of the educated groups, while IV results show that less educated workers are less responsive to demand shocks than the more educated. Second, the agricultural Hukou subgroups are generally more responsive to demand shifts than those with non-agricultural Hukou, both in terms of population and working hours. Third, young workers are more responsive to demand shifts than old workers in terms of population change and vice versa in terms of changes in working hours. In addition, neither of the estimated coefficients for the old workers with non-agricultural Hukou is significant, suggesting that they do not respond to local demand shifts through migration across regions.

Table 10 presents OLS results for the urban sample after we adjust working time as above. Similar to Table 7, less educated workers are more responsive to local demand shifts than the educated subgroups. Results also show that the subgroups with agricultural Hukou are more responsive to demand shifts than those with non-agricultural Hukou. Also, the coefficients on population adjustment for the less

\footnotetext{
${ }^{17}$ Hours fewer than eight but more than zero are treated as one day, and days more than seven are regarded as seven days.
} 
educated subgroups with agricultural Hukou are all significantly greater than one, suggesting agglomeration or multiplying effects. The predicted growth of city working hours remains uncorrelated with actual changes of city working hours for the urban sample, and the IV results are not reported.

To circumvent the comparability issue of working time, we also consider population independently and measure population adjustment for each demographic group with changes in population size. The procedure of regressions, including standardization, remains the same as before. As for the demand shifts, we use growth in local population size as a proxy. Similarly, to exclude the supply effect we construct an instrumental variable as follows:

$$
\hat{\delta}_{k}=\sum_{j} \rho_{j k} \delta_{j}
$$

where $\hat{\delta}_{k}$ represents predicted growth of population size in city k, $\rho_{j k}$ represents the share of population size accounted for by industry $j$ in city $k$ in 2000 , and $\delta_{j}$ represents the national change in the $\log$ of population size in industry $j$ between 2000 and 2005.

Figure 6 shows a significant positive correlation between predicted growth in the local labor force population and the actual growth of the local population, suggesting that the instrumental variable is relevant. Specifically, the regression result is as follows:

$$
\text { city_ } \text { popu }_{k}=0.013+0.878 \hat{\delta}_{k} \quad \mathrm{~F}(1,306)=19, R^{2}=0.06
$$

Table 11 presents the second stage results of IV and OLS results. The results are generally consistent with our previous conclusions. First, OLS results show that the population adjustments of the less educated groups are more associated with total population change than that of the educated groups, while IV results show that less educated workers are less responsive to demand shocks than the more educated. Second, the agricultural Hukou subgroups are generally more responsive to demand shifts than 
those with non-agricultural Hukou both in terms of population and working hours. Finally, young workers are more responsive to demand shifts than old workers in terms of population change and vice versa in terms of changes of working hours.

Our conclusions are robust to whether we have two or four age categories, and we do not report the results here.

\section{Discussion and Implications}

\section{Skill bias in local demand shifts}

The differential results across demographic groups that we find in the above analysis may also be caused by skill biased demand shifts. In this case, even when educated and less educated workers face comparable net benefits of migration, their migration rates differ. Several pieces of evidence suggest that demand shifts are skill biased. First, as we observe in the changes of the industrial structure, the IT industry is the fastest growing industry while the traditional agricultural sector is shrinking. Second, a major change occurred between 2000 and 2005-China entered the WTO. Existing research shows that China's export products have become increasingly sophisticated. The increased FDI also requires more educated labor.

Given the skill biased local demand shifts, our results also indicate that the less educated are less responsive to demand shocks, at least for the old subgroups and the subgroups with non-agricultural Hukou. To see this point, we can think of a model with two regions, A and B. Each region has a CES production function with educated and less educated labor as inputs. A wage increase of the educated labor in region A will attract educated labor from region $\mathrm{B}$, which will in turn increase the marginal product of less educated workers in region A and decrease their marginal product in region B. Thus, less educated workers will also migrate from B to A if migration costs are sufficiently low. However, our IV results show that the coefficients are mostly insignificant when we examine changes in population of the low education groups, the young, and the less educated workers, with agricultural Hukou being an exception. This 
suggests that the less educated workers face significant migration costs, especially for those with non-agricultural Hukou.

If the local demand shifts are not skill biased, which is unlikely, it will only strengthen our conclusion that the less educated are not responsive to regional demand shocks in terms of population adjustment.

\section{How does Hukou system impede migration?}

A major finding of this paper is that populations with non-agricultural Hukou are far less responsive to demand shocks than populations with agricultural Hukou, which suggests that the Hukou system restricts the mobility of the former group to a larger extent. To the best of our knowledge, this feature has not been discussed in the literature. Most studies emphasize the role of Hukou system in restricting rural to urban migration. However, as we discuss in the background section, one's Hukou status also specifies the locality of formal residency, which is associated with many locally provided benefits. Thus, when an individual with non-agricultural Hukou migrates without obtaining the Hukou status of his or her destination region, he or she would have to sacrifice those local benefits. These high opportunity costs lead to the inertia of non-agricultural workers facing regional demand shocks. When migration happens, non-agricultural migrants are expected to earn more than local urban residents. The difference can be regarded as the compensation for the loss of Hukou-related benefits. Workers with agricultural Hukou are more responsive to demand shocks, because income is low and benefits are few for agricultural Hukou workers. Even without a wage premium, they migrate as long as the income differential surpasses migration costs.

These hypotheses can be tested by examining the incomes of different types of workers in the urban labor market. Using the one percent population survey for 2005, we identify three types of workers based on their migration and Hukou status: rural migrants, urban migrants, and urban residents. Two questions in the questionnaire are used to identify migrants in the urban labor market: (1) In which location is your Hukou 
registered? (2) How long ago did you leave this location? Migrants are defined as those who have left their registered Hukou location for more than six months. Another question asks the type of Hukou (agricultural or non-agricultural) and helps divide migrants further into two categories. As individuals with an agricultural Hukou usually come from rural areas, we refer to this group as rural migrants. Similarly, we refer to migrants with non-agricultural Hukou as urban migrants, as most of them come from urban areas. We refer to residents who have local urban Hukou as urban residents. In addition, the questionnaire asks the reason for migrating. Most migrants said they had moved for work, and this is especially true for rural migrants (the share is approximately 61 percent). We restrict our sample to those who migrated for work or for business related reasons. The sample studied in the following analysis includes individuals from 16 to 60 years of age and who are not currently in school. Employers, household workers, and observations with no or zero declared income are not considered.

Summary statistics for these three groups are reported in Table 12. One can readily tell that urban migrants earn more than urban residents, while rural migrants earn less than urban residents. Figure 7 provides a more comprehensive comparison by estimating the kernel densities of hourly wages for these three groups. We also observe that these three groups differ in education levels, age, and female share. We run OLS regressions to control for these differences. The results in Table 13 show that an average urban migrant earns 16 percent more than an urban resident with similar characteristics. This difference can be interpreted as the value of benefits associated with urban local Hukou that has been sacrificed. When we control for industry and occupation dummies in the second column, the wage difference between urban migrants and urban residents increases to 20 percent. In the third column, we add interaction terms to allow for the possibility that age, education, gender, marital status, and region have different effects on wages for the three subgroups. The result indicates that urban migrants still earn significantly more than urban residents by around 11 percent. As for rural migrants, although they earn significantly less than urban residents on average, the difference disappears once we control for industry and occupation. 
When we add interaction terms to allow for the different effects of personal and regional characteristics on wage determination, rural migrants earn slightly more than urban residents. The difference between the estimated coefficients on rural migrants and those on urban migrants strongly suggests that the importable benefits associated with local Hukou are significantly higher for urban residents than for rural residents. It not only amplifies the welfare difference between rural and urban residents, but also discourages the urban residents from migrating. The latter effect is largely neglected by the literature, and we want to emphasize it in this paper.

\section{Conclusion}

China's economic growth is regionally unbalanced. The pattern of labor force adjustment is not only important in explaining several features of China’s labor market, but also has major implications for the sustainability of China's growth. In this paper, we use two nationally representative census datasets for 2000 and 2005 to examine the population adjustment of different demographic groups in response to local demand shifts.

Results from OLS regressions show that the population adjustments of the less educated groups are more associated with changes in total city working hours than that of the educated groups. This explains why we observe increases in the skill premia of coastal regions after China's entry into the WTO. These results, however, does not necessarily mean that the former groups are more responsive to demand shocks, because changes in city working hours also reflect other forces such as exogenous supply shocks. Using an IV strategy, we find that more educated workers are more responsive to demand shocks than the less educated, which is consistent with the prevailing view. In addition, old subgroups are particularly inert in responding to demand shocks.

Our results also suggest that the decentralized Hukou system prevents the mobility of urban residents more than it does for rural residents. This finding deepens our understanding of the role of the Hukou system in restricting labor mobility. It also 
indicates that reforming the Hukou system should not focus only on abolishing the agricultural vs. non-agricultural division, but also on the decentralized features of the system.

\section{References}

Amiti M, Freund C. “An anatomy of China's export growth Global Implications of China’s Trade,” Investment and Growth Conference, IMF Research Department, 2008.

Bartik, Timothy. 1991. Who Benefits from State and Local Economic Development Policies? Kalamazoo, Mich.: W. E. Upjohn Institute.

Blanchard, Olivier, and Katz, Lawrence. 1992. "Regional Evolutions,” Brookings Papers on Economic Activity, 1992(1): 1-61.

Bound, John, and Holzer, Harry J., 2000. "Demand Shifts, Population Adjustments, and Labor Market Outcomes During the 1980s,” Journal of Labor Economics, 18 (1): $20-54$.

Branstetter, Lee, and Nicholas Lardy. 2006. “China’s Embrace of Globalization,” NBER Working Paper No. 12373.

Cai, Fang, Yang Du, and Meiyang Wang. 2009. "Migration and Labor Mobility in China,” Human Development Research Paper, 2009/09.

Chan, Kam Wing, and Will Buckingham. 2008. "Is China Abolishing the Hukou System?” China Quarterly, (195):582-606.

Chen, Jian, and Belton M. Fleisher. 1996. "Regional Income Inequality and Economic Growth in China,” Journal of Comparative Economics,22(2): 141-164

Deng, Q, and Gustafsson B. 2006.“China's Lesser Known Migrants.”IZA Discussion Papers 2152, IZA.

Fan, C. 2008.China on the Move: Migration, the State, and the Household. Routledge, London and New York.

Gagnon, Jason, Theodora Xenogiani, and Chunbing Xing, "Are Migrants

Discriminated Against in Chinese Urban Labour Markets?” IZA Journal of Labor and Development, 2014, 3:17.

Gustafsson, B, Shi Li, Terry Sicular, and Ximing Yue. 2008. "Income Inequality and Spatial Differences in China, 1988, 1995, and 2002,” in Gustafsson B, Shi Li, Terry Sicular (ed), Inequality and Public Policy in China, Cambridge University Press.

Kanbur R, Zhang X. "Fifty years of regional inequality in China: a journey through central planning, reform, and openness," Review of development Economics, 2005, 9(1): 87-106. 
Lin, J.Y., G. W. Wang, Y. H. Zhao, 2004, “Regional Inequality and Labor Transfers in China”, Economic Development and Cultural Change, 52(3):587-603.

National Bureau of Statistics. 2008. China Statistical Yearbook. China Statistics Press.

Schott, Peter. 2006. “The Relative Sophistication of Chinese Exports,” NBER Working Paper No. 12173.

Topel, Robert. 1986. “Local Labor Markets,” Journal of Political Economy 94(3): S111-S143.

Whalley, John, and Chunbing Xing, 2014, "The Regional Distribution of the Skill Premia in Urban China and its Implications for Growth and Inequality,” International Labour Review, 153(3): 395-420.

Wan, Guanghua, Ming Lu, and Zhao Chen. 2007. “Globalization and Regional Income Inequality in China, Empirical Evidence from within China,” Review of Income and Wealth, 53(3): 35-59

Wang, Zhi, and Shang-Jin Wei. 2008. "What Accounts for the Rising Sophistication of China’s Exports?” NBER Working Paper No. 13771.

Wei, Shang-Jin and Yi Wu. 2003. "Globalization and Inequality: Evidence from within China,” CEPR Discussion Paper No. 3088.

Wong, L, and Huen W. 1998.'Reforming the Household Registration System: a Preliminary Glimpse of the Blue Chop Household Registration System in Shanghai and Shenzhen.”International Migration Review 32(4): 974-994

Wu, X, and Treiman D. 2004. "The Household Registration System and Social Stratification of China, 1955-1996.” Demography 41(2):363-384

Zhang, Xiaobo, and Kevin Zhang. 2003. "How Does Globalization Affect Regional Inequality within a Developing Country? Evidence from China,” Journal of Development Studies 39(4): 47-67.

Zhao, Y. 1997. "Labor Migration and Education in Rural Sichuan Province,” Economic Research Journal (Jingji Yanjiu), 2: 37-42, (In Chinese) 
Table 1 Summary Statistics

\begin{tabular}{lll}
\hline & 2000 & 2005 \\
\hline Age & 34.67 & 35.96 \\
Male & 0.540 & 0.534 \\
Primary School or below & 0.355 & 0.304 \\
Junior high school & 0.453 & 0.468 \\
Senior high school & 0.140 & 0.144 \\
College or above & 0.052 & 0.084 \\
Hours worked weekly & 47.01 & 46.29 \\
Urban Hukou & 0.223 & 0.249 \\
No. of obs. & 568257 & 1212914 \\
\hline
\end{tabular}


Table 2 Growth in total hours worked and labor force population across provinces (unit: 1 million)

\begin{tabular}{|c|c|c|c|c|c|c|}
\hline \multirow[t]{2}{*}{ Province } & \multicolumn{3}{|c|}{ Total working hours } & \multicolumn{3}{|c|}{ Labor force population } \\
\hline & 2000 & 2005 & Growth rate $(\%)$ & 2000 & 2005 & Growth rate (\%) \\
\hline Inner mongolia & 446.17 & 528.59 & 18.47 & 8.87 & 12.00 & 35.26 \\
\hline Fujian & 714.19 & 829.41 & 16.13 & 16.07 & 16.80 & 4.49 \\
\hline Guangdong & 2148.39 & 2422.56 & 12.76 & 43.60 & 48.41 & 11.01 \\
\hline Tianjin & 209.33 & 232.14 & 10.90 & 4.46 & 5.00 & 11.96 \\
\hline Zhejiang & 1118.61 & 1220.06 & 9.07 & 24.39 & 24.02 & -1.52 \\
\hline Shanghai & 353.47 & 382.48 & 8.21 & 8.01 & 8.57 & 7.00 \\
\hline Ningxia & 127.12 & 134.99 & 6.19 & 2.69 & 2.99 & 10.99 \\
\hline Hainan & 165.57 & 174.17 & 5.19 & 3.46 & 3.86 & 11.55 \\
\hline Hebei & 1324.89 & 1388.93 & 4.83 & 28.78 & 34.59 & 20.18 \\
\hline Heilongjiang & 700.13 & 714.59 & 2.07 & 14.51 & 17.14 & 18.13 \\
\hline Jiangsu & 1809.98 & 1846.93 & 2.04 & 39.00 & 37.40 & -4.08 \\
\hline Beijing & 325.61 & 330.07 & 1.37 & 6.91 & 7.24 & 4.69 \\
\hline Shaanxi & 750.67 & 759.08 & 1.12 & 16.53 & 17.90 & 8.28 \\
\hline Jiangxi & 838.48 & 844.76 & 0.75 & 17.53 & 18.21 & 3.87 \\
\hline Anhui & 1331.02 & 1321.16 & -0.74 & 29.44 & 29.52 & 0.25 \\
\hline Xinjiang & 446.07 & 440.59 & -1.23 & 9.11 & 9.66 & 6.03 \\
\hline Hubei & 1217.82 & 1196.93 & -1.72 & 26.58 & 26.46 & -0.46 \\
\hline Shandong & 2364.89 & 2293.86 & -3.00 & 50.64 & 47.97 & -5.26 \\
\hline Yunnan & 1221.99 & 1163.03 & -4.83 & 23.40 & 24.04 & 2.77 \\
\hline Hunan & 1319.93 & 1220.82 & -7.51 & 29.53 & 28.89 & -2.18 \\
\hline Jilin & 591.32 & 543.15 & -8.15 & 12.13 & 12.13 & 0.03 \\
\hline Qinghai & 135.22 & 124.03 & -8.28 & 2.53 & 2.61 & 3.15 \\
\hline Shanxi & 649.41 & 593.30 & -8.64 & 14.71 & 14.61 & -0.68 \\
\hline Liaoning & 915.32 & 813.33 & -11.14 & 21.33 & 19.71 & -7.60 \\
\hline Chongqing & 652.66 & 577.91 & -11.45 & 13.99 & 12.31 & -12.03 \\
\hline Sichuan & 1899.62 & 1670.37 & -12.07 & 40.99 & 36.88 & -10.02 \\
\hline Guizhou & 855.51 & 744.06 & -13.03 & 17.57 & 16.28 & -7.36 \\
\hline Guangxi & 1109.18 & 964.48 & -13.05 & 21.62 & 20.64 & -4.56 \\
\hline Gansu & 670.01 & 569.28 & -15.03 & 13.20 & 12.86 & -2.58 \\
\hline Henan & 2275.23 & 1887.79 & -17.03 & 48.70 & 44.80 & -8.00 \\
\hline
\end{tabular}

Note: The data in 2005 is weighted by sampling weights. 
Table 3 Labor Market Outcomes by Demographic Group: 2000-2005 (Means and Standard Deviations)

\begin{tabular}{|c|c|c|c|c|c|c|c|c|c|c|c|c|c|}
\hline & & \multicolumn{3}{|c|}{ Primary school or less } & \multicolumn{3}{|c|}{ Junior high school } & \multicolumn{3}{|c|}{ Senior High school } & \multicolumn{3}{|c|}{ College or above } \\
\hline & & Hours & Population & $\begin{array}{l}\text { Total } \\
\text { Hours }\end{array}$ & Hours & Population & $\begin{array}{l}\text { Total } \\
\text { Hours }\end{array}$ & Hours & Population & $\begin{array}{l}\text { Total } \\
\text { Hours }\end{array}$ & Hours & Population & $\begin{array}{l}\text { Total } \\
\text { Hours }\end{array}$ \\
\hline \multirow[t]{6}{*}{ All experience group } & Male \& Female & -0.05 & -0.23 & -0.28 & -0.02 & 0.07 & 0.06 & 0.00 & -0.02 & -0.02 & 0.01 & 0.34 & 0.35 \\
\hline & & $(0.23)$ & $(0.69)$ & $(0.72)$ & $(0.17)$ & $(0.61)$ & $(0.61)$ & $(0.16)$ & $(0.73)$ & $(0.74)$ & $(0.13)$ & $(0.71)$ & $(0.73)$ \\
\hline & Male & -0.02 & -0.26 & -0.27 & 0.00 & 0.02 & 0.02 & 0.01 & -0.02 & -0.00 & 0.01 & 0.25 & 0.26 \\
\hline & & $(0.20)$ & $(0.70)$ & $(0.72)$ & $(0.15)$ & $(0.58)$ & $(0.58)$ & $(0.14)$ & $(0.72)$ & $(0.73)$ & $(0.14)$ & $(0.70)$ & $(0.72)$ \\
\hline & Female & -0.09 & -0.20 & -0.29 & -0.04 & 0.13 & 0.09 & -0.01 & -0.02 & -0.03 & 0.00 & 0.44 & 0.45 \\
\hline & & $(0.24)$ & $(0.67)$ & $(0.71)$ & $(0.18)$ & $(0.63)$ & $(0.64)$ & $(0.17)$ & $(0.74)$ & $(0.76)$ & $(0.12)$ & $(0.71)$ & $(0.72)$ \\
\hline \multirow[t]{6}{*}{ Age group: 36-54 } & Male \& Female & -0.05 & -0.05 & -0.10 & -0.02 & 0.31 & 0.29 & -0.00 & 0.20 & 0.19 & 0.01 & 0.46 & 0.47 \\
\hline & & $(0.22)$ & $(0.65)$ & $(0.67)$ & $(0.17)$ & $(0.57)$ & $(0.57)$ & $(0.16)$ & $(0.72)$ & $(0.73)$ & $(0.10)$ & (0.69) & $(0.70)$ \\
\hline & Male & -0.01 & -0.08 & -0.09 & 0.01 & 0.25 & 0.25 & 0.01 & 0.23 & 0.24 & 0.01 & 0.39 & 0.40 \\
\hline & & $(0.20)$ & $(0.65)$ & $(0.66)$ & $(0.15)$ & $(0.50)$ & $(0.52)$ & $(0.14)$ & (0.69) & $(0.70)$ & $(0.10)$ & $(0.67)$ & $(0.67)$ \\
\hline & Female & -0.09 & -0.02 & -0.11 & -0.04 & 0.37 & 0.33 & -0.02 & 0.16 & 0.14 & 0.00 & 0.56 & 0.56 \\
\hline & & $(0.23)$ & $(0.65)$ & $(0.68)$ & $(0.18)$ & $(0.62)$ & $(0.62)$ & $(0.18)$ & $(0.74)$ & $(0.75)$ & $(0.09)$ & $(0.72)$ & $(0.73)$ \\
\hline \multirow[t]{6}{*}{ Age group: 16-35 } & Male \& Female & -0.06 & -0.46 & -0.52 & -0.02 & -0.16 & -0.17 & 0.01 & -0.22 & -0.22 & 0.01 & 0.24 & 0.25 \\
\hline & & $(0.23)$ & $(0.67)$ & $(0.70)$ & $(0.17)$ & $(0.56)$ & $(0.56)$ & $(0.15)$ & $(0.69)$ & $(0.70)$ & $(0.16)$ & $(0.71)$ & $(0.73)$ \\
\hline & Male & -0.03 & -0.49 & -0.52 & 0.00 & -0.21 & -0.21 & 0.02 & -0.26 & -0.24 & 0.01 & 0.13 & 0.14 \\
\hline & & $(0.21)$ & $(0.70)$ & $(0.73)$ & $(0.15)$ & $(0.56)$ & $(0.56)$ & $(0.15)$ & $(0.66)$ & $(0.68)$ & $(0.17)$ & $(0.72)$ & $(0.74)$ \\
\hline & Female & -0.08 & -0.43 & -0.52 & -0.03 & -0.10 & -0.14 & -0.00 & -0.18 & -0.19 & 0.00 & 0.36 & 0.36 \\
\hline & & $(0.26)$ & $(0.63)$ & $(0.69)$ & $(0.18)$ & $(0.55)$ & $(0.56)$ & $(0.16)$ & $(0.71)$ & $(0.73)$ & $(0.14)$ & (0.69) & $(0.71)$ \\
\hline
\end{tabular}

Note: All variables are measured as changes in logs, 2000-2005; Standard deviations in parentheses 
Table 4 Effects of demand on outcomes by age and education-full sample (agricultural and non-agricultural)

\begin{tabular}{|c|c|c|c|c|c|c|}
\hline \multirow{4}{*}{ Dep Var= } & $(1)$ & $(2)$ & (3) & (4) & (5) & (6) \\
\hline & \multicolumn{3}{|l|}{ OLS } & \multicolumn{3}{|l|}{ IV } \\
\hline & Hours & Population & Total & Hours & Population & Total \\
\hline & & & Hours & & & Hours \\
\hline \multicolumn{7}{|c|}{ All age: High education } \\
\hline \multirow[t]{2}{*}{ city_hour } & $0.075^{* * *}$ & $0.771^{* * *}$ & $0.847 * * *$ & $0.193 * * *$ & $0.979 * * *$ & $1.176^{* * *}$ \\
\hline & $(0.013)$ & $(0.041)$ & $(0.042)$ & $(0.033)$ & $(0.099)$ & $(0.107)$ \\
\hline $\mathrm{R} 2$ & 0.101 & 0.533 & 0.568 & . & 0.494 & 0.481 \\
\hline \multicolumn{7}{|c|}{ All age: Low education } \\
\hline \multirow[t]{2}{*}{ city_hour } & $0.159 * * *$ & $0.867 * * *$ & $1.025 * * *$ & $0.482 * * *$ & 0.153 & $0.633^{* * *}$ \\
\hline & $(0.028)$ & $(0.038)$ & $(0.025)$ & $(0.077)$ & $(0.128)$ & $(0.077)$ \\
\hline $\mathrm{R} 2$ & 0.094 & 0.63 & 0.847 & . & 0.202 & 0.723 \\
\hline \multicolumn{7}{|c|}{ Young group: High education } \\
\hline \multirow[t]{2}{*}{ city_hour } & $0.079 * * *$ & $0.840 * * *$ & $0.921 * * *$ & $0.221^{* * *}$ & $1.398 * * *$ & $1.624 * * *$ \\
\hline & $(0.014)$ & $(0.055)$ & $(0.056)$ & $(0.037)$ & $(0.146)$ & $(0.159)$ \\
\hline $\mathrm{R} 2$ & 0.098 & 0.433 & 0.468 & . & 0.242 & 0.195 \\
\hline \multicolumn{7}{|c|}{ Young group: Low education } \\
\hline \multirow[t]{2}{*}{ city_hour } & $0.176^{* * *}$ & $0.982 * * *$ & $1.157^{* * *}$ & $0.591^{* * *}$ & $0.513^{* * *}$ & $1.102^{* * *}$ \\
\hline & $(0.029)$ & $(0.050)$ & $(0.036)$ & $(0.087)$ & $(0.130)$ & $(0.083)$ \\
\hline $\mathrm{R} 2$ & 0.105 & 0.56 & 0.771 & . & 0.432 & 0.769 \\
\hline \multicolumn{7}{|c|}{ Old group: High education } \\
\hline \multirow[t]{2}{*}{ city_hour } & $0.069 * * *$ & $0.692 * * *$ & $0.762 * * *$ & $0.154^{* * *}$ & $0.460 * * *$ & $0.617^{* * *}$ \\
\hline & $(0.014)$ & $(0.055)$ & $(0.055)$ & $(0.034)$ & $(0.129)$ & $(0.129)$ \\
\hline $\mathrm{R} 2$ & 0.074 & 0.344 & 0.382 & . & 0.305 & 0.368 \\
\hline \multicolumn{7}{|c|}{ Old group: Low education } \\
\hline \multirow[t]{2}{*}{ city_hour } & $0.136^{* * *}$ & $0.764 * * *$ & $0.900 * * *$ & $0.346 * * *$ & -0.141 & 0.203 \\
\hline & $(0.027)$ & $(0.043)$ & $(0.039)$ & $(0.069)$ & $(0.155)$ & $(0.129)$ \\
\hline $\mathrm{R} 2$ & 0.075 & 0.511 & 0.63 & . & . & 0.252 \\
\hline
\end{tabular}

Note: (1) All variables are measured as changes in logs between 2000 and 2005; (2) Standard errors in parentheses;

(3) Sample size=308; (4) *, **, and *** represent significance levels of $10 \%, 5 \%$, and $1 \%$, respectively. 
Table 5 Effects of demand on outcomes by age and education for agricultural Hukou sample

\begin{tabular}{|c|c|c|c|c|c|c|}
\hline \multirow{4}{*}{ Dep Var= } & $(1)$ & $(2)$ & (3) & (4) & (5) & (6) \\
\hline & \multicolumn{3}{|l|}{ OLS } & \multicolumn{3}{|l|}{ IV } \\
\hline & Hours & Population & Total & Hours & Population & Total \\
\hline & & & Hours & & & Hours \\
\hline \multicolumn{7}{|c|}{ All age: High education } \\
\hline \multirow[t]{2}{*}{ city_hour } & $0.130 * * *$ & $0.773^{* * *}$ & $0.903 * * *$ & $0.386 * * *$ & $1.213^{* * *}$ & $1.603^{* * *}$ \\
\hline & $(0.027)$ & $(0.071)$ & $(0.077)$ & $(0.070)$ & $(0.173)$ & $(0.199)$ \\
\hline $\mathrm{R} 2$ & 0.073 & 0.279 & 0.313 & . & 0.188 & 0.125 \\
\hline \multicolumn{7}{|c|}{ All age: Low education } \\
\hline \multirow[t]{2}{*}{ city_hour } & $0.163^{* * *}$ & $0.879 * * *$ & $1.041^{* * *}$ & $0.522 * * *$ & $0.218^{*}$ & $0.738 * * *$ \\
\hline & $(0.033)$ & $(0.043)$ & $(0.030)$ & $(0.090)$ & $(0.133)$ & $(0.079)$ \\
\hline $\mathrm{R} 2$ & 0.074 & 0.572 & 0.801 & . & 0.249 & 0.734 \\
\hline \multicolumn{7}{|c|}{ Young group: High education } \\
\hline \multirow[t]{2}{*}{ city_hour } & $0.145^{* * *}$ & $0.929 * * *$ & $1.075^{* * *}$ & $0.471^{* * *}$ & $1.449 * * *$ & $1.930 * * *$ \\
\hline & $(0.027)$ & $(0.099)$ & $(0.104)$ & $(0.076)$ & $(0.239)$ & $(0.265)$ \\
\hline $\mathrm{R} 2$ & 0.086 & 0.223 & 0.258 & . & 0.153 & 0.094 \\
\hline \multicolumn{7}{|c|}{ Young group: Low education } \\
\hline \multirow[t]{2}{*}{ city_hour } & $0.184^{* * *}$ & $1.024 * * *$ & $1.207 * * *$ & $0.626 * * *$ & $0.561^{* * *}$ & $1.185^{* * *}$ \\
\hline & $(0.034)$ & $(0.056)$ & $(0.042)$ & $(0.097)$ & $(0.143)$ & $(0.096)$ \\
\hline $\mathrm{R} 2$ & 0.089 & 0.523 & 0.733 & . & 0.416 & 0.733 \\
\hline \multicolumn{7}{|c|}{ Old group: High education } \\
\hline \multirow[t]{2}{*}{ city_hour } & $0.128 * * *$ & $0.615 * * *$ & $0.744 * * *$ & $0.314 * * *$ & $0.838 * * *$ & $1.156^{* * *}$ \\
\hline & $(0.032)$ & $(0.084)$ & $(0.091)$ & $(0.077)$ & $(0.196)$ & $(0.216)$ \\
\hline $\mathrm{R} 2$ & 0.051 & 0.148 & 0.18 & . & 0.129 & 0.124 \\
\hline \multicolumn{7}{|c|}{ Old group: Low education } \\
\hline \multirow[t]{2}{*}{ city_hour } & $0.136 * * *$ & $0.735^{* * *}$ & $0.870 * * *$ & $0.383^{* * *}$ & -0.093 & $0.289 * *$ \\
\hline & $(0.033)$ & $(0.047)$ & $(0.042)$ & $(0.083)$ & $(0.153)$ & $(0.124)$ \\
\hline $\mathrm{R} 2$ & 0.052 & 0.446 & 0.579 & . & . & 0.321 \\
\hline
\end{tabular}

Note: (1) All variables are measured as changes in logs between 2000 and 2005; (2) Standard errors in parentheses;

(3) Sample size=308; (4) *, **, and *** represent significance levels of $10 \%, 5 \%$, and $1 \%$, respectively. 
Table 6 Effects of demand on outcomes by age and education for non-agricultural Hukou sample

\begin{tabular}{|c|c|c|c|c|c|c|}
\hline \multirow{4}{*}{ Dep Var= } & $(1)$ & $(2)$ & (3) & (4) & (5) & (6) \\
\hline & \multicolumn{3}{|l|}{ OLS } & \multicolumn{3}{|l|}{ IV } \\
\hline & Hours & Population & Total & Hours & Population & Total \\
\hline & & & Hours & & & Hours \\
\hline \multicolumn{7}{|c|}{ All age: High education } \\
\hline \multirow[t]{2}{*}{ city_hour } & $0.039 * * *$ & $0.749 * * *$ & $0.789 * * *$ & $0.072 * * *$ & $0.936 * * *$ & $1.013^{* * *}$ \\
\hline & $(0.010)$ & $(0.060)$ & $(0.060)$ & $(0.023)$ & $(0.140)$ & $(0.141)$ \\
\hline $\mathrm{R} 2$ & 0.048 & 0.339 & 0.361 & 0.014 & 0.318 & 0.332 \\
\hline \multicolumn{7}{|c|}{ All age: Low education } \\
\hline \multirow[t]{2}{*}{ city_hour } & $0.085 * * *$ & $0.610 * * *$ & $0.695 * * *$ & $0.210 * * *$ & 0.048 & 0.258 \\
\hline & $(0.017)$ & $(0.087)$ & $(0.090)$ & $(0.043)$ & $(0.214)$ & $(0.215)$ \\
\hline $\mathrm{R} 2$ & 0.072 & 0.138 & 0.164 & . & 0.021 & 0.099 \\
\hline \multicolumn{7}{|c|}{ Young group: High education } \\
\hline \multirow[t]{2}{*}{ city_hour } & $0.039 * * *$ & $0.815^{* * * *}$ & $0.855^{* * *}$ & $0.073 * * *$ & $1.450 * * *$ & $1.529 * * *$ \\
\hline & $(0.012)$ & $(0.071)$ & $(0.072)$ & $(0.027)$ & $(0.184)$ & $(0.187)$ \\
\hline $\mathrm{R} 2$ & 0.035 & 0.3 & 0.318 & 0.007 & 0.119 & 0.121 \\
\hline \multicolumn{7}{|c|}{ Young group: Low education } \\
\hline \multirow[t]{2}{*}{ city_hour } & $0.072 * * *$ & $0.622 * * *$ & $0.695 * * *$ & $0.203^{* * *}$ & $0.416^{*}$ & $0.622 * * *$ \\
\hline & $(0.020)$ & $(0.094)$ & $(0.097)$ & $(0.050)$ & $(0.218)$ & $(0.224)$ \\
\hline $\mathrm{R} 2$ & 0.039 & 0.126 & 0.143 & . & 0.112 & 0.141 \\
\hline \multicolumn{7}{|c|}{ Old group: High education } \\
\hline \multirow[t]{2}{*}{ city_hour } & $0.039 * * *$ & $0.659 * * *$ & $0.699 * * *$ & $0.073 * * *$ & 0.214 & 0.29 \\
\hline & $(0.011)$ & $(0.075)$ & $(0.075)$ & $(0.026)$ & $(0.182)$ & $(0.181)$ \\
\hline $\mathrm{R} 2$ & 0.039 & 0.202 & 0.221 & 0.01 & 0.11 & 0.145 \\
\hline \multicolumn{7}{|c|}{ Old group: Low education } \\
\hline \multirow[t]{2}{*}{ city_hour } & $0.100^{* * *}$ & $0.603 * * *$ & $0.703^{* * *}$ & $0.221 * * *$ & -0.173 & 0.043 \\
\hline & $(0.020)$ & $(0.098)$ & $(0.101)$ & $(0.048)$ & $(0.248)$ & $(0.248)$ \\
\hline $\mathrm{R} 2$ & 0.079 & 0.11 & 0.137 & . & . & 0.016 \\
\hline
\end{tabular}

Note: (1) All variables are measured as changes in logs between 2000 and 2005; (2) Standard errors in parentheses;

(3) Sample size=308; (4) *, **, and *** represent significance levels of $10 \%, 5 \%$, and $1 \%$, respectively. 
Table 7 Effects of demand on outcomes by age and education for urban sample (OLS)

\begin{tabular}{|c|c|c|c|c|c|c|c|c|c|c|}
\hline & & $(1)$ & $(2)$ & $(3)$ & $(4)$ & $(5)$ & $(6)$ & $(7)$ & $(8)$ & $(9)$ \\
\hline & & \multicolumn{3}{|l|}{ All age } & \multicolumn{3}{|l|}{ Young } & \multicolumn{3}{|l|}{ Old } \\
\hline & & Hours & Population & Total & Hours & Population & Total & Hours & Population & Total \\
\hline & & & & Hours & & & Hours & & & Hours \\
\hline \multirow[t]{3}{*}{ Agricultural \& Non-agri: High education } & city_hour & $0.038 * * *$ & $0.717 * * *$ & $0.756^{* * *}$ & $0.029 * * *$ & $0.720 * * *$ & $0.750 * * *$ & $0.048 * * *$ & $0.706^{* * *}$ & $0.755^{* * *}$ \\
\hline & & $(0.009)$ & $(0.040)$ & $(0.040)$ & $(0.010)$ & $(0.054)$ & $(0.054)$ & $(0.010)$ & $(0.053)$ & $(0.053)$ \\
\hline & r2 & 0.057 & 0.516 & 0.544 & 0.027 & 0.371 & 0.391 & 0.072 & 0.364 & 0.4 \\
\hline \multirow[t]{3}{*}{ Agricultural \& Non-agri: Low education } & city_hour & $0.075^{* * *}$ & $1.019^{* * *}$ & $1.095^{* * *}$ & $0.069 * * *$ & $1.005^{* * *}$ & $1.074 * * *$ & $0.082^{* * *}$ & $1.022^{* * *}$ & $1.105^{* * *}$ \\
\hline & & $(0.019)$ & $(0.034)$ & $(0.028)$ & $(0.021)$ & $(0.044)$ & $(0.039)$ & $(0.019)$ & $(0.044)$ & $(0.041)$ \\
\hline & r2 & 0.048 & 0.75 & 0.837 & 0.035 & 0.634 & 0.713 & 0.06 & 0.635 & 0.698 \\
\hline \multirow[t]{3}{*}{ Agricultural: High education } & city_hour & $0.069 * * *$ & $0.709 * * *$ & $0.781 * * *$ & 0.045 & $0.704^{* * *}$ & $0.747 * * *$ & $0.103^{* * *}$ & $0.710 * * *$ & $0.821 * * *$ \\
\hline & & $(0.026)$ & $(0.104)$ & $(0.108)$ & $(0.029)$ & $(0.127)$ & $(0.132)$ & $(0.033)$ & $(0.117)$ & $(0.119)$ \\
\hline & r2 & 0.022 & 0.132 & 0.145 & 0.008 & 0.091 & 0.095 & 0.03 & 0.107 & 0.134 \\
\hline \multirow[t]{3}{*}{ Agricultural: Low education } & city_hour & $0.074 * * *$ & $1.033^{* * *}$ & $1.107^{* * *}$ & $0.073 * * *$ & $1.049 * * *$ & $1.124 * * *$ & $0.080^{* * *}$ & $1.005^{* * *}$ & $1.085^{* * *}$ \\
\hline & & $(0.025)$ & $(0.054)$ & $(0.050)$ & $(0.025)$ & $(0.061)$ & $(0.058)$ & $(0.026)$ & $(0.067)$ & $(0.064)$ \\
\hline & r2 & 0.029 & 0.548 & 0.619 & 0.026 & 0.493 & 0.552 & 0.031 & 0.425 & 0.485 \\
\hline \multirow[t]{3}{*}{ Non-agricultural: High education } & city_hour & $0.029 * * *$ & $0.681^{* * *}$ & $0.711^{* * *}$ & $0.021 * *$ & $0.674 * * *$ & $0.697 * * *$ & $0.038 * * *$ & $0.689 * * *$ & $0.727 * * *$ \\
\hline & & $(0.008)$ & $(0.049)$ & $(0.048)$ & $(0.009)$ & $(0.061)$ & $(0.060)$ & $(0.009)$ & $(0.062)$ & $(0.062)$ \\
\hline & r2 & 0.044 & 0.39 & 0.42 & 0.017 & 0.284 & 0.304 & 0.056 & 0.285 & 0.313 \\
\hline \multirow[t]{3}{*}{ Non-agricultural: Low education } & city_hour & $0.063 * * *$ & $0.850 * * *$ & $0.913^{* * *}$ & $0.056 * * *$ & $0.748 * * *$ & $0.804 * * *$ & $0.073 * * *$ & $0.916 * * *$ & $0.988 * * *$ \\
\hline & & $(0.013)$ & $(0.063)$ & $(0.064)$ & $(0.016)$ & $(0.071)$ & $(0.072)$ & $(0.015)$ & $(0.075)$ & $(0.077)$ \\
\hline & r2 & 0.067 & 0.37 & 0.4 & 0.04 & 0.265 & 0.292 & 0.072 & 0.325 & 0.351 \\
\hline
\end{tabular}

Note: (1) All variables are measured as changes in logs between 2000 and 2005; (2) Standard errors in parentheses; (3) Sample size=308; (4) *, **, and *** represent significance levels of 10\%,

$5 \%$, and $1 \%$, respectively. 
Table 8 Effects of demand on outcomes by age and education for agricultural Hukou sample (based on days)

\begin{tabular}{|c|c|c|c|c|c|c|}
\hline \multirow[b]{3}{*}{ Dep Var= } & $(1)$ & $(2)$ & (3) & (4) & (5) & (6) \\
\hline & \multicolumn{3}{|l|}{ OLS } & \multicolumn{3}{|l|}{ IV } \\
\hline & Days & Population & Total Days & Days & Population & Total Days \\
\hline \multicolumn{7}{|c|}{ All age: High education } \\
\hline \multirow[t]{2}{*}{ city_day } & $0.078 * * *$ & $0.798^{* * *}$ & $0.877 * * *$ & $0.284 * * *$ & $1.434^{* * *}$ & $1.722 * * *$ \\
\hline & $(0.026)$ & $(0.074)$ & $(0.080)$ & $(0.074)$ & $(0.217)$ & $(0.244)$ \\
\hline R2 & 0.03 & 0.273 & 0.284 & . & 0.1 & 0.021 \\
\hline \multicolumn{7}{|c|}{ All age: Low education } \\
\hline \multirow[t]{2}{*}{ city_day } & $0.097 * * *$ & $0.939 * * *$ & $1.035^{* * *}$ & $0.359 * * *$ & $0.258^{*}$ & $0.615^{* * *}$ \\
\hline & $(0.032)$ & $(0.044)$ & $(0.031)$ & $(0.093)$ & $(0.153)$ & $(0.103)$ \\
\hline $\mathrm{R} 2$ & 0.029 & 0.6 & 0.781 & . & 0.285 & 0.653 \\
\hline \multicolumn{7}{|c|}{ Young group: High education } \\
\hline \multirow[t]{2}{*}{ city_day } & $0.098^{* * *}$ & $0.971^{* * *}$ & $1.069 * * *$ & $0.371^{* * *}$ & $1.712^{* * *}$ & $2.093 * * *$ \\
\hline & $(0.026)$ & $(0.103)$ & $(0.109)$ & $(0.080)$ & $(0.293)$ & $(0.323)$ \\
\hline $\mathrm{R} 2$ & 0.044 & 0.223 & 0.241 & . & 0.094 & 0.019 \\
\hline \multicolumn{7}{|c|}{ Young group: Low education } \\
\hline \multirow[t]{2}{*}{ city_day } & $0.109 * * *$ & $1.089 * * *$ & $1.198 * * *$ & $0.437 * * *$ & $0.667 * * *$ & $1.102 * * *$ \\
\hline & $(0.032)$ & $(0.057)$ & $(0.043)$ & $(0.097)$ & $(0.162)$ & $(0.114)$ \\
\hline $\mathrm{R} 2$ & 0.037 & 0.543 & 0.715 & . & 0.462 & 0.71 \\
\hline \multicolumn{7}{|c|}{ Old group: High education } \\
\hline \multirow[t]{2}{*}{ city_day } & $0.070^{* *}$ & $0.621^{* * *}$ & $0.691^{* * *}$ & $0.202^{* *}$ & $0.989 * * *$ & $1.193 * * *$ \\
\hline & $(0.031)$ & $(0.088)$ & $(0.094)$ & $(0.083)$ & $(0.238)$ & $(0.257)$ \\
\hline $\mathrm{R} 2$ & 0.017 & 0.139 & 0.15 & . & 0.09 & 0.071 \\
\hline \multicolumn{7}{|c|}{ Old group: Low education } \\
\hline \multirow[t]{2}{*}{ city_day } & $0.080^{* *}$ & $0.790^{* * *}$ & $0.870^{* * *}$ & $0.249 * * *$ & -0.11 & 0.136 \\
\hline & $(0.033)$ & $(0.048)$ & $(0.044)$ & $(0.090)$ & $(0.184)$ & $(0.160)$ \\
\hline $\mathrm{R} 2$ & 0.019 & 0.473 & 0.556 & . & . & 0.161 \\
\hline
\end{tabular}

Note: (1) All variables are measured as changes in logs between 2000 and 2005; (2) Standard errors in parentheses;

(3) Sample size=308; (4) *, **, and *** represent significance levels of $10 \%, 5 \%$, and $1 \%$, respectively. 
Table 9 Effects of demand on outcomes by age and education for non-agricultural Hukou sample (based on days)

\begin{tabular}{|c|c|c|c|c|c|c|}
\hline \multirow[b]{3}{*}{ Dep Var= } & $(1)$ & $(2)$ & (3) & (4) & (5) & (6) \\
\hline & \multicolumn{3}{|l|}{ OLS } & \multicolumn{3}{|l|}{ IV } \\
\hline & Days & Population & Total Days & Days & Population & Total Days \\
\hline \multicolumn{7}{|c|}{ All age: High education } \\
\hline \multirow[t]{2}{*}{ city_day } & $0.024 * *$ & $0.773 * * *$ & $0.797 * * *$ & $0.043^{*}$ & $1.105^{* * *}$ & $1.152 * * *$ \\
\hline & $(0.009)$ & $(0.063)$ & $(0.063)$ & $(0.025)$ & $(0.172)$ & $(0.173)$ \\
\hline R2 & 0.02 & 0.331 & 0.344 & 0.007 & 0.27 & 0.276 \\
\hline \multicolumn{7}{|c|}{ All age: Low education } \\
\hline \multirow[t]{2}{*}{ city_day } & $0.040^{* * *}$ & $0.626 * * *$ & $0.666 * * *$ & $0.126^{* * *}$ & 0.046 & 0.171 \\
\hline & $(0.015)$ & $(0.091)$ & $(0.093)$ & $(0.042)$ & $(0.254)$ & $(0.254)$ \\
\hline $\mathrm{R} 2$ & 0.022 & 0.134 & 0.144 & . & 0.019 & 0.064 \\
\hline \multicolumn{7}{|c|}{ Young group: High education } \\
\hline \multirow[t]{2}{*}{ city_day } & $0.024 * *$ & $0.838 * * *$ & $0.863 * * *$ & 0.046 & $1.715^{* * *}$ & $1.766^{* * *}$ \\
\hline & $(0.011)$ & $(0.075)$ & $(0.075)$ & $(0.029)$ & $(0.236)$ & $(0.239)$ \\
\hline $\mathrm{R} 2$ & 0.015 & 0.291 & 0.301 & 0.003 & . & . \\
\hline \multicolumn{7}{|c|}{ Young group: Low education } \\
\hline \multirow[t]{2}{*}{ city_day } & 0.029 & $0.640 * * *$ & $0.669 * * *$ & $0.102 * *$ & $0.487 *$ & $0.591 * *$ \\
\hline & $(0.019)$ & $(0.098)$ & $(0.101)$ & $(0.050)$ & $(0.258)$ & $(0.264)$ \\
\hline $\mathrm{R} 2$ & 0.008 & 0.122 & 0.126 & . & 0.115 & 0.124 \\
\hline \multicolumn{7}{|c|}{ Old group: High education } \\
\hline \multirow[t]{2}{*}{ city_day } & $0.022 * *$ & $0.690 * * *$ & $0.713^{* * *}$ & 0.037 & 0.256 & 0.294 \\
\hline & $(0.010)$ & $(0.078)$ & $(0.078)$ & $(0.027)$ & $(0.214)$ & $(0.214)$ \\
\hline $\mathrm{R} 2$ & 0.015 & 0.204 & 0.214 & 0.008 & 0.123 & 0.14 \\
\hline \multicolumn{7}{|c|}{ Old group: Low education } \\
\hline \multirow[t]{2}{*}{ city_day } & $0.054 * * *$ & $0.623^{* * *}$ & $0.676^{* * *}$ & $0.144^{* * *}$ & -0.216 & -0.077 \\
\hline & $(0.017)$ & $(0.103)$ & $(0.105)$ & $(0.048)$ & $(0.297)$ & $(0.296)$ \\
\hline $\mathrm{R} 2$ & $0.022 * *$ & $0.690 * * *$ & $0.713^{* * *}$ & 0.037 & 0.256 & 0.294 \\
\hline
\end{tabular}

Note: (1) All variables are measured as changes in logs between 2000 and 2005; (2) Standard errors in parentheses;

(3) Sample size=308; (4) *, **, and *** represent significance levels of $10 \%, 5 \%$, and $1 \%$, respectively. 
Table 10 Effects of demand on outcomes by age and education for urban sample (OLS-based on days)

\begin{tabular}{|c|c|c|c|c|c|c|c|c|c|c|}
\hline \multirow[b]{3}{*}{ Dep Var= } & & $(1)$ & $(2)$ & $(3)$ & $(4)$ & $(5)$ & $(6)$ & $(7)$ & $(8)$ & $(9)$ \\
\hline & & \multicolumn{3}{|l|}{ All age } & \multicolumn{3}{|l|}{ Young } & \multicolumn{3}{|l|}{ Old } \\
\hline & & Days & Population & Total Days & Days & Population & Total Days & Days & Population & Total Days \\
\hline \multirow[t]{3}{*}{ Agricultural \& Non-agri: High education } & city_day & $0.025^{* * *}$ & $0.717^{* * *}$ & $0.742 * * *$ & $0.018^{* *}$ & $0.715^{* * *}$ & $0.733 * * *$ & $0.034 * * *$ & $0.717 * * *$ & $0.750 * * *$ \\
\hline & & $(0.008)$ & $(0.041)$ & $(0.041)$ & $(0.009)$ & $(0.055)$ & $(0.055)$ & $(0.009)$ & $(0.054)$ & $(0.054)$ \\
\hline & r2 & 0.032 & 0.498 & 0.52 & 0.013 & 0.353 & 0.367 & 0.046 & 0.362 & 0.389 \\
\hline \multirow[t]{3}{*}{ Agricultural \& Non-agri: Low education } & city_day & $0.045^{* * *}$ & $1.056^{* * *}$ & $1.100^{* * *}$ & $0.041 * *$ & $1.041^{* * *}$ & $1.082 * * *$ & $0.050 * * *$ & $1.057 * * *$ & $1.107 * * *$ \\
\hline & & $(0.016)$ & $(0.032)$ & $(0.029)$ & $(0.017)$ & $(0.043)$ & $(0.040)$ & $(0.016)$ & $(0.044)$ & $(0.042)$ \\
\hline & $\mathrm{r} 2$ & 0.026 & 0.778 & 0.828 & 0.019 & 0.658 & 0.709 & 0.031 & 0.657 & 0.693 \\
\hline \multirow[t]{3}{*}{ Agricultural: High education } & city_day & $0.049 * *$ & $0.716^{* * *}$ & $0.767 * * *$ & 0.038 & $0.705^{* * *}$ & $0.741^{* * *}$ & $0.073^{* *}$ & $0.736^{* * *}$ & $0.816^{* * *}$ \\
\hline & & $(0.025)$ & $(0.106)$ & $(0.110)$ & $(0.027)$ & $(0.129)$ & $(0.133)$ & $(0.031)$ & $(0.119)$ & $(0.120)$ \\
\hline & $\mathrm{r} 2$ & 0.013 & 0.13 & 0.137 & 0.007 & 0.089 & 0.092 & 0.018 & 0.111 & 0.131 \\
\hline \multirow[t]{3}{*}{ Agricultural: Low education } & city_day & $0.046 * *$ & $1.078^{* * *}$ & $1.124^{* * *}$ & $0.045^{* *}$ & $1.090^{* * *}$ & $1.138 * * *$ & $0.051 * *$ & $1.052 * * *$ & $1.103^{* * *}$ \\
\hline & & $(0.022)$ & $(0.053)$ & $(0.051)$ & $(0.022)$ & $(0.060)$ & $(0.059)$ & $(0.024)$ & $(0.067)$ & $(0.066)$ \\
\hline & r2 & 0.014 & 0.576 & 0.612 & 0.014 & 0.515 & 0.549 & 0.015 & 0.449 & 0.479 \\
\hline \multirow[t]{3}{*}{ Non-agricultural: High education } & city_day & $0.021^{* * *}$ & $0.676^{* * *}$ & $0.697 * * *$ & $0.015^{*}$ & $0.665^{* * *}$ & $0.680^{* * *}$ & $0.028 * * *$ & $0.697 * * *$ & $0.724 * * *$ \\
\hline & & $(0.007)$ & $(0.050)$ & $(0.049)$ & $(0.009)$ & $(0.063)$ & $(0.062)$ & $(0.008)$ & $(0.063)$ & $(0.063)$ \\
\hline & $\mathrm{r} 2$ & 0.027 & 0.372 & 0.398 & 0.01 & 0.267 & 0.283 & 0.037 & 0.282 & 0.304 \\
\hline \multirow[t]{3}{*}{ Non-agricultural: Low education } & city_day & $0.035^{* * *}$ & $0.854 * * *$ & $0.889 * * *$ & $0.032 * *$ & $0.750 * * *$ & $0.782 * * *$ & $0.041^{* * *}$ & $0.924^{* * *}$ & $0.966 * * *$ \\
\hline & & $(0.011)$ & $(0.065)$ & $(0.065)$ & $(0.014)$ & $(0.073)$ & $(0.072)$ & $(0.013)$ & $(0.077)$ & $(0.078)$ \\
\hline & r2 & 0.029 & 0.361 & 0.381 & 0.017 & 0.257 & 0.276 & 0.033 & 0.321 & 0.336 \\
\hline
\end{tabular}

Note: (1) All variables are measured as changes in logs between 2000 and 2005; (2) Standard errors in parentheses; (3) Sample size=308; (4) *, **, and *** represent significance levels of 10\%, 5\%, and $1 \%$, respectively. 
Table 11 Effects of demand on outcomes by age and education, considering population only

\begin{tabular}{|c|c|c|c|c|c|c|}
\hline \multirow[b]{3}{*}{ Dep Var= } & \multicolumn{2}{|l|}{ full } & \multicolumn{2}{|l|}{ agricultural } & \multicolumn{2}{|c|}{ non-agricultural } \\
\hline & OLS & IV & OLS & IV & OLS & IV \\
\hline & Population & Population & Population & Population & Population & Population \\
\hline \multicolumn{7}{|c|}{ All age: High education } \\
\hline \multirow[t]{2}{*}{ city_popu } & $0.741^{* * *}$ & $1.813^{* * *}$ & $0.741 * * *$ & $2.275^{* * *}$ & $0.714^{* * *}$ & $1.755^{* * *}$ \\
\hline & $(0.048)$ & $(0.321)$ & $(0.078)$ & $(0.482)$ & $(0.066)$ & $(0.366)$ \\
\hline $\mathrm{R} 2$ & 0.437 & . & 0.229 & . & 0.275 & . \\
\hline \multicolumn{7}{|c|}{ All age: Low education } \\
\hline \multirow[t]{2}{*}{ city_popu } & $1.071^{* * *}$ & 0.327 & $1.106 * * *$ & $0.456^{* *}$ & $0.591^{* * *}$ & 0.035 \\
\hline & $(0.026)$ & $(0.204)$ & $(0.031)$ & $(0.199)$ & $(0.093)$ & $(0.405)$ \\
\hline $\mathrm{R} 2$ & 0.852 & 0.441 & 0.808 & 0.529 & 0.116 & 0.014 \\
\hline \multicolumn{7}{|c|}{ Young group: High education } \\
\hline \multirow[t]{2}{*}{ city_popu } & $0.796 * * *$ & $2.626 * * *$ & $0.848 * * *$ & $2.692 * * *$ & $0.769 * * *$ & $2.739 * * *$ \\
\hline & $(0.063)$ & $(0.501)$ & $(0.109)$ & $(0.622)$ & $(0.078)$ & $(0.565)$ \\
\hline $\mathrm{R} 2$ & 0.347 & . & 0.166 & . & 0.239 & . \\
\hline \multicolumn{7}{|c|}{ Young group: Low education } \\
\hline \multirow[t]{2}{*}{ city_popu } & $1.229 * * *$ & $1.013^{* * *}$ & $1.294^{* * *}$ & $1.097 * * *$ & $0.601^{* * *}$ & $0.748^{*}$ \\
\hline & $(0.037)$ & $(0.161)$ & $(0.043)$ & $(0.182)$ & $(0.101)$ & $(0.415)$ \\
\hline $\mathrm{R} 2$ & 0.783 & 0.758 & 0.749 & 0.732 & 0.104 & 0.098 \\
\hline \multicolumn{7}{|c|}{ Old group: High education } \\
\hline \multirow[t]{2}{*}{ city_popu } & $0.693 * * *$ & $0.825^{* * *}$ & $0.619 * * *$ & $1.558 * * *$ & $0.662 * * *$ & 0.448 \\
\hline & $(0.060)$ & $(0.247)$ & $(0.090)$ & $(0.431)$ & $(0.080)$ & $(0.333)$ \\
\hline $\mathrm{R} 2$ & 0.306 & 0.295 & 0.134 & . & 0.183 & 0.164 \\
\hline \multicolumn{7}{|c|}{ Old group: Low education } \\
\hline \multirow[t]{2}{*}{ city_popu } & $0.925^{* * *}$ & -0.195 & $0.919 * * *$ & -0.103 & $0.594 * * *$ & -0.332 \\
\hline & $(0.038)$ & $(0.306)$ & $(0.042)$ & $(0.295)$ & $(0.104)$ & $(0.482)$ \\
\hline $\mathrm{R} 2$ & 0.661 & . & 0.615 & . & 0.096 & . \\
\hline
\end{tabular}

Note: (1) All variables are measured as changes in logs between 2000 and 2005; (2) Standard errors in parentheses;

(3) Sample size=308; (4) *, **, and *** represent significance levels of $10 \%, 5 \%$, and $1 \%$, respectively. 
Table 12 Summary statistics of urban residents, rural migrants, and urban migrants

\begin{tabular}{llll}
\hline Variable & $\begin{array}{l}\text { Urban } \\
\text { residents }\end{array}$ & $\begin{array}{l}\text { Migrants with } \\
\text { agricultural } \\
\text { Hukou }\end{array}$ & $\begin{array}{l}\text { Migrants with } \\
\text { Non-agricultural } \\
\text { Hukou }\end{array}$ \\
\hline Age & 38.0 & 30.3 & 32.1 \\
Female (\%) & 41.7 & 41.7 & 41.1 \\
Education level (\%) & & & \\
Primary and below & 6.0 & 20.5 & 5.0 \\
Junior middle school & 31.1 & 62.5 & 31.4 \\
Senior middle school & 33.0 & 15.2 & 36.0 \\
College and above & 29.9 & 1.8 & 27.6 \\
Monthly income & 1062.0 & 973.7 & 1527.4 \\
Hourly income & 6.1 & 4.6 & 8.3 \\
No unemployment insurance (\%) & 58.1 & 94.1 & 74.4 \\
No pension (\%) & 38.3 & 87.8 & 59.1 \\
No medical insurance (\%) & 37.8 & 83.8 & 62.4 \\
Obs. & 219710 & 94621 & 22213 \\
\hline
\end{tabular}

Source: Calculated from 2005 one percent population survey.

Table 13 Wage differential between different types of workers

\begin{tabular}{llll}
\hline Dependent variable=log(hourly income) & & & \\
\hline Rural migrants & $(1)$ & $(2)$ & $(3)$ \\
& $-0.030^{* * *}$ & -0.001 & $0.038^{*}$ \\
Urban migrants & $(0.003)$ & $(0.003)$ & $(0.021)$ \\
& $0.157^{* * *}$ & $0.190^{* * *}$ & $0.105^{* * *}$ \\
Age category & $(0.004)$ & $(0.004)$ & $(0.036)$ \\
Gender & yes & yes & yes \\
Education levels & yes & yes & yes \\
Marital status & yes & yes & yes \\
Province & yes & yes & yes \\
Industry and occupation & yes & yes & yes \\
Interaction terms & no & yes & no \\
R-squared & no & no & yes \\
$\mathrm{N}$ & 0.342 & 0.393 & 0.351 \\
\hline
\end{tabular}






Figure 1 Changes in the log of total working hours by industry 

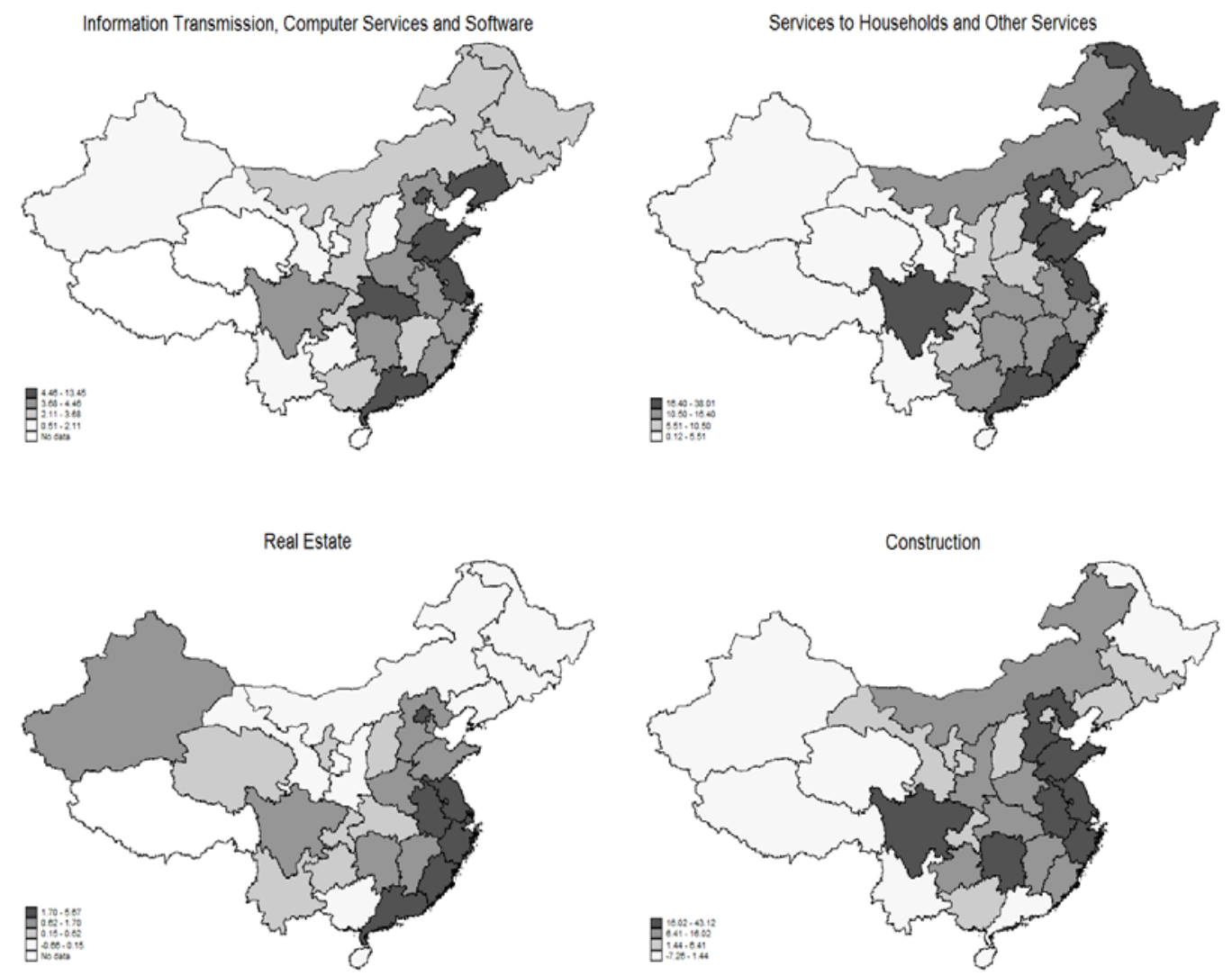

Figure 2 Growth in total working hours by industry across provinces 




Figure 3 Predicted growth in working hours and the actual growth of working hours

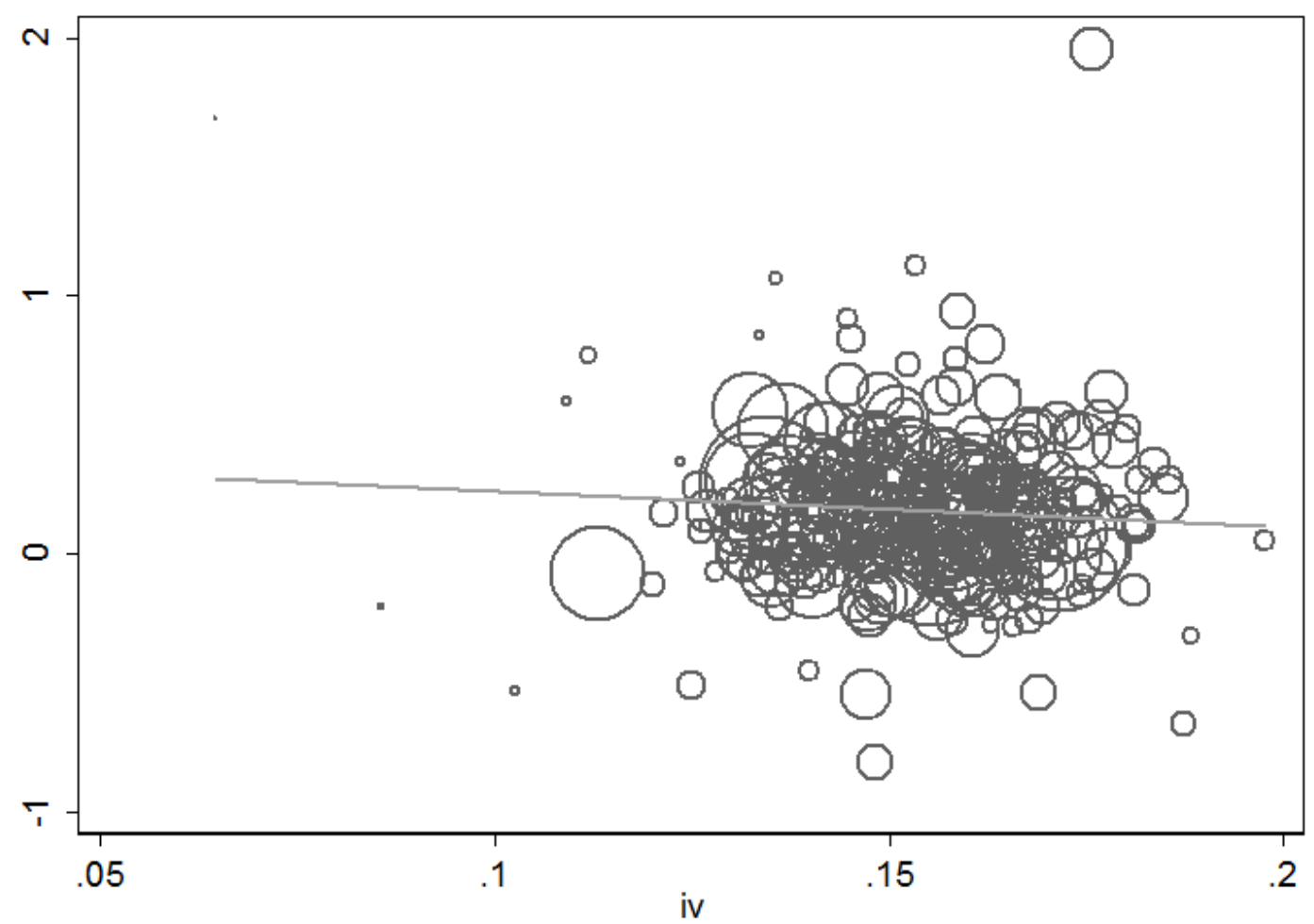

Figure 4 Predicted growth in working hours and the actual growth of total working hours (urban area) 

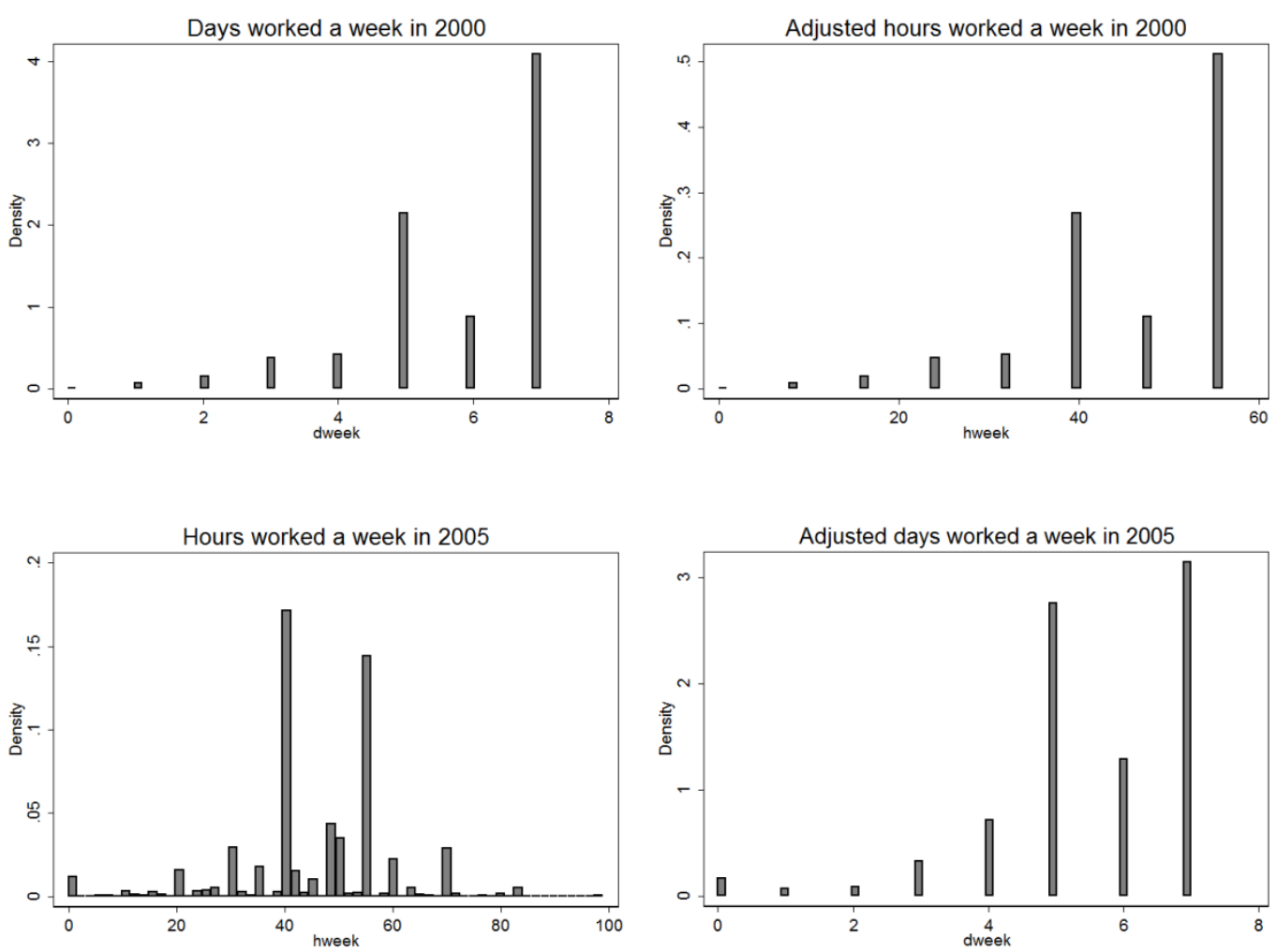

Figure 5 Distribution of working time in 2000 and 2005

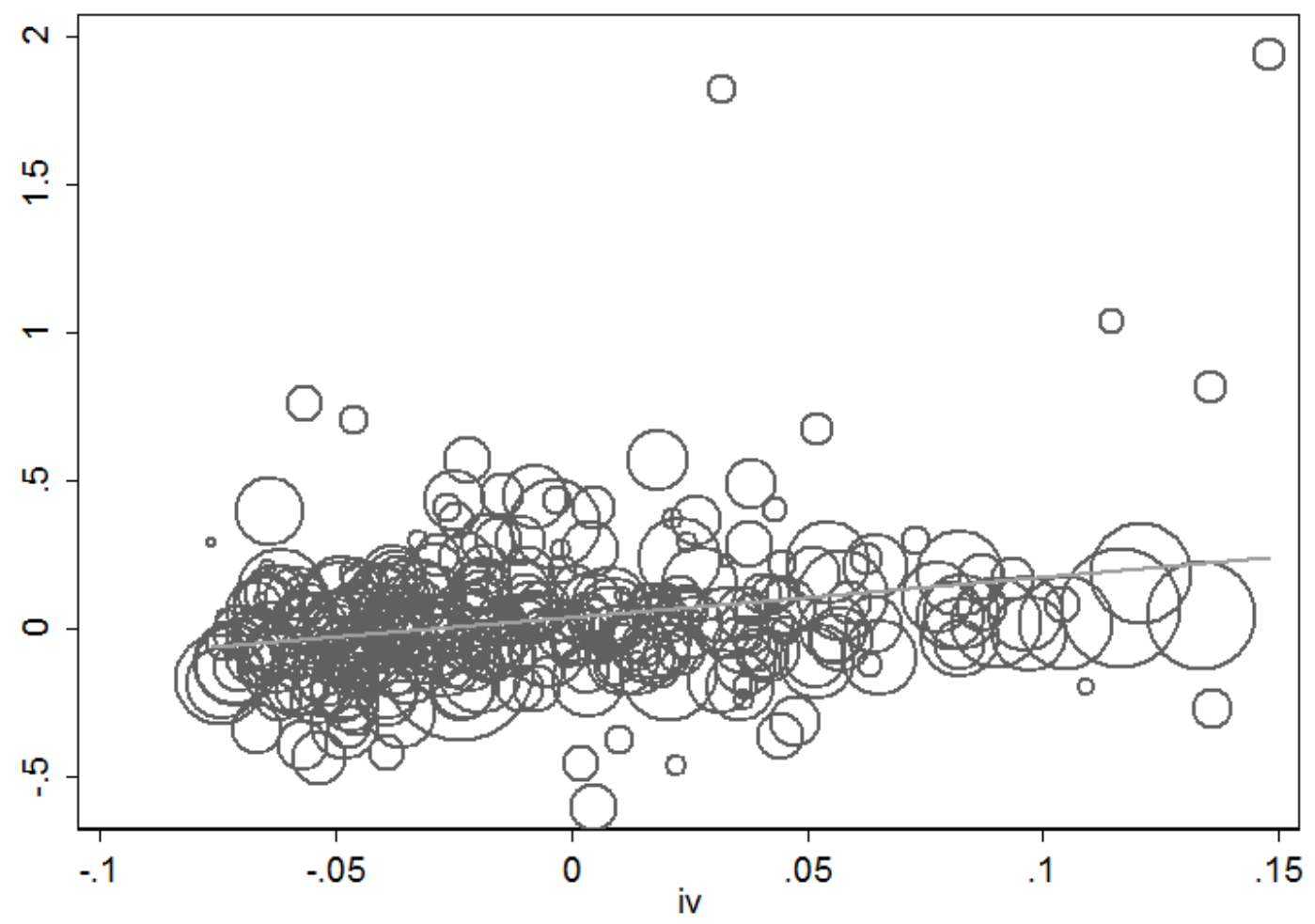

Figure 6 Predicted growth in labor force population and the actual growth of population 


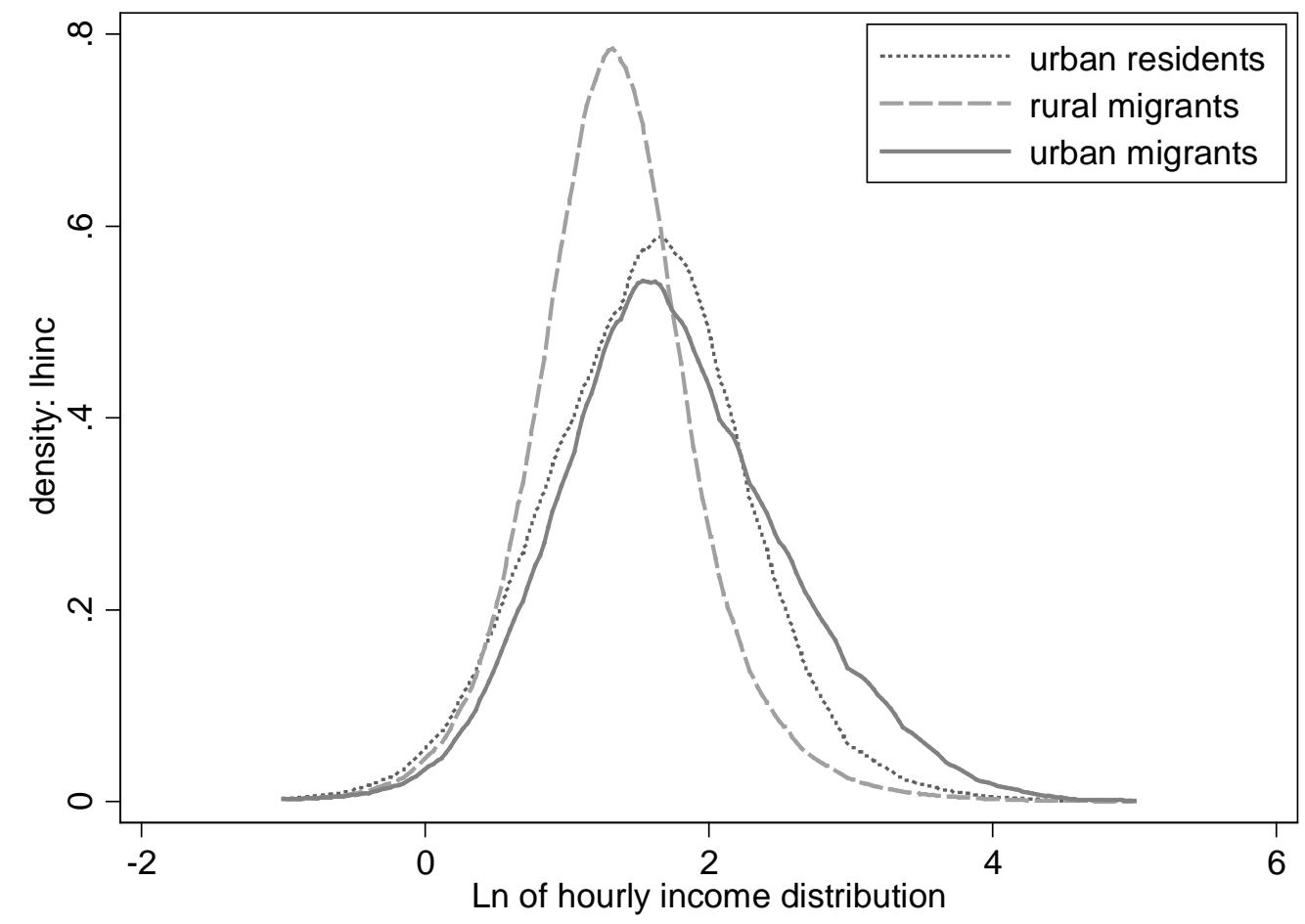

Figure 7 Income distributions of different types of workers in China's urban labor market 


\section{Appendix}

Unemployment rates and labor participation rates in urban China between 2000 and 2005

\begin{tabular}{|c|c|c|c|c|}
\hline \multirow[t]{2}{*}{ Province } & \multicolumn{2}{|c|}{ Unemployment rate (\%) } & \multicolumn{2}{|c|}{ Labor participation rate (\%) } \\
\hline & 2000 & 2005 & 2000 & 2005 \\
\hline Beijing & 0.8 & 2.1 & 81.38 & 81.10 \\
\hline Tianjin & 3.2 & 3.7 & 80.47 & 79.38 \\
\hline Hebei & 2.8 & 3.9 & 81.88 & 85.10 \\
\hline Shanxi & 2.2 & 3 & 86.37 & 85.15 \\
\hline Inner mongolia & 3.3 & 4.3 & 84.35 & 84.24 \\
\hline Liaoning & 3.7 & 5.6 & 84.27 & 85.96 \\
\hline Jilin & 3.7 & 4.2 & 80.35 & 81.04 \\
\hline Heilongjiang & 3.3 & 4.4 & 83.97 & 82.38 \\
\hline Shanghai & 3.5 & 4.4 & 81.81 & 84.52 \\
\hline Jiangsu & 3.2 & 3.6 & 85.72 & 87.93 \\
\hline Zhejiang & 3.5 & 3.7 & 88.88 & 90.65 \\
\hline Anhui & 3.3 & 4.4 & 86.07 & 87.35 \\
\hline Fujian & 2.6 & 4 & 89.86 & 89.77 \\
\hline Jiangxi & 2.9 & 3.5 & 86.25 & 87.93 \\
\hline Shandong & 3.2 & 3.3 & 86.43 & 88.39 \\
\hline Henan & 2.6 & 3.5 & 84.94 & 84.62 \\
\hline Hubei & 3.5 & 4.3 & 83.45 & 84.72 \\
\hline Hunan & 3.7 & 4.3 & 84.77 & 84.78 \\
\hline Guangdong & 2.5 & 2.6 & 91.09 & 88.83 \\
\hline Guangxi & 3.2 & 4.2 & 85.14 & 86.30 \\
\hline Hainan & 3.2 & 3.6 & 87.25 & 84.48 \\
\hline Chongqing & 3.5 & 4.1 & 86.55 & 86.73 \\
\hline Sichuan & 4 & 4.6 & 84.56 & 86.91 \\
\hline Guizhou & 3.8 & 4.2 & 84.89 & 86.78 \\
\hline Yunnan & 2.6 & 4.2 & 86.90 & 87.94 \\
\hline Shaanxi & 2.7 & 4.2 & 82.34 & 83.70 \\
\hline Gansu & 2.7 & 3.3 & 85.27 & 85.02 \\
\hline Qinghai & 2.4 & 3.9 & 89.19 & 84.02 \\
\hline Ningxia & 4.6 & 4.5 & 87.60 & 87.21 \\
\hline Xinjiang & 3.8 & 3.9 & 84.20 & 86.73 \\
\hline
\end{tabular}

Note: (1) Unemployment rate is the registered unemployment rate in urban areas (Source: National Bureau of Statistics of China); (2) Labor participation rate is calculated from datasets used in this paper, and the data in 2005 is weighted by sampling weights. 